\title{
Therapeutic applications of low-toxicity spherical nanocarbon materials
}

\author{
Jing Wang ${ }^{1,2}$, Zhongbo $\mathrm{Hu}^{2}$, Jianxun $\mathrm{Xu}^{1}$ and Yuliang $\mathrm{Zhao}^{1}$
}

\begin{abstract}
Nanocarbon materials have received considerable attention due to their unique structure and properties, which make them promising candidate materials for use in biomedical applications. In this review, we discuss the therapeutic applications of spherical nanocarbon materials, including fullerene nanoparticles, carbon nanohorn aggregates, nanodiamonds and porous carbon nanospheres, and their toxicology in biological systems. We put special emphasis on the antitumor effects of these multifunctional nanoparticles, which operate via novel mechanisms in a highly efficient manner. The low toxicities of these spherical nanocarbon materials as well as the possible effects of shape on toxicity are discussed.
\end{abstract} NPG Asia Materials (2014) 6, e84; doi:10.1038/am.2013.79; published online 7 February 2014

Keywords: carbon nanohorns; fullerenes; nanodiamonds; nanotherapy; nanotoxicology

\section{INTRODUCTION}

In recent years, there has been tremendous development in the field of nano-biomedical research, particularly in the use of engineered nanomaterials in biomedical applications. ${ }^{1-3}$ These novel materials, which exhibit unique structures and properties, have been useful in many biosystems as diagnostic probes, nanocarriers and biomarkers. $^{4-7}$ Owing to their small size, it is possible to use nanomaterials to probe, adjust and control biological processes at the cellular and subcellular level. In particular, manufactured nanocarbon materials, including fullerenes, carbon nanotubes, carbon nanohorns and graphene, have been shown to be extremely useful in various biology-related applications such as nanomedicine, drug delivery and biolabeling. ${ }^{8-12}$ For example, Nakamura et al. ${ }^{13,14}$ recently described how functionalized fullerenes could be used to deliver the green fluorescent protein gene in vitro and in vivo; higher gene expression was found in the liver and spleen. This research points toward the possible application of fullerenes as novel agents for gene therapy. Carbon nanotubes and carbon nanohorns were both demonstrated to be promising candidates for drug delivery and controlled release, showing high drug-loading capacity and extended blood circulation times. ${ }^{8,15}$ Additionally, nanodiamonds have recently emerged as a novel platform for drug delivery, imaging and sensing, showing enhanced therapeutic efficacy, photostable fluorescence and high biocompatibility. ${ }^{16-18}$ As a relatively new member of the nanocarbon materials family, graphene also exhibits possible applications in biomedical schemes, such as drug delivery and regenerative medicine. ${ }^{19,20}$ There are already many reports that discuss the properties and biomedical applications of carbon nanotubes, graphene and even amorphous carbon nanoparticles. ${ }^{21-24}$
In this review, we focus on the therapeutic applications (nanomedicine and drug delivery) of spherical nanocarbon materials, mainly fullerene nanoparticles, carbon nanohorn aggregates, nanodiamonds and porous carbon nanospheres (Figure 1). These nanocarbon materials have distinct structures, comprising $\mathrm{SP}^{2}$ or $\mathrm{SP}^{3}$ hybridized carbons. All of these nanocarbon materials exist as round nanoparticles in the aqueous phase with diameters ranging from tens of nanometers to hundreds of nanometers, in contrast to both cylindrical carbon nanotubes, which have a high aspect ratio and two-dimensional planar graphene. In addition, we compare the toxicities of these spherical nanocarbon materials. The possible effect of shape on the biological properties and toxicity of these materials are described based on literature reports.

\section{FULLERENES AND METALLOFULLERENES}

Pristine fullerenes, including $\mathrm{C}_{60}, \mathrm{C}_{70}, \mathrm{C}_{82}$ and so on, are a family of cage-like molecules consisting of 12 pentagonal carbon rings isolated and fused by six-membered carbon rings. They can be produced by laser ablation or arc discharge using high-purity graphite as the carbon source. When a metal atom or cluster is encapsulated inside a fullerene cage (mainly a Group III transition element or lanthanide), the structure is called an endohedral metallofullerene. Examples of such structures include Li@ $\mathrm{C}_{60}, \mathrm{Sc}_{3} \mathrm{~N} @ \mathrm{C}_{82}, \mathrm{Gd} @ \mathrm{C}_{82}$ and so on. ${ }^{25}$ Endohedral metallofullerenes are synthesized by arc discharge in a specific atmosphere (for example, helium or nitrogen) using a mixture of graphite and a metal alloy powder as the discharge anode. In addition, exohedral additions of various molecules to the outer surface of the cage also can produce a variety of fullerene derivatives. Endohedral and exohedral modifications dramatically

${ }^{1}$ Chinese Academy of Sciences Key Laboratory for Biomedical Effects of Nanomaterials and Nanosafety, National Center for Nanosciences and Technology of China, Beijing, China and ${ }^{2}$ College of Materials Science and Opto-Electronic Technology, University of Chinese Academy of Sciences, Beijing, China

Correspondence: Dr J Xu or Professor Y Zhao, Chinese Academy of Sciences Key Laboratory for Biomedical Effects of Nanomaterials and Nanosafety, National Center for Nanosciences and Technology of China, No. 11, Bei yi tiao, Zhong Guan Cun, Beijing 100190, China.

E-mail: xujx@nanoctr.cn or zhaoy|@nanoctr.cn

Received 9 September 2013; revised 5 November 2013; accepted 6 November 2013 
a

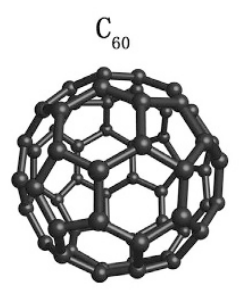

C

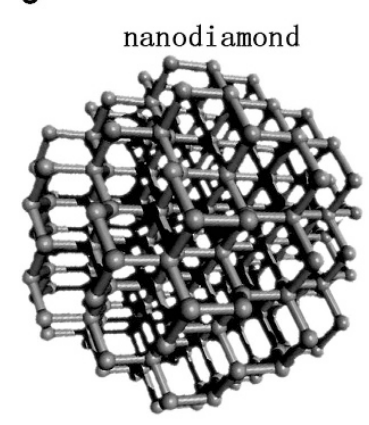

b

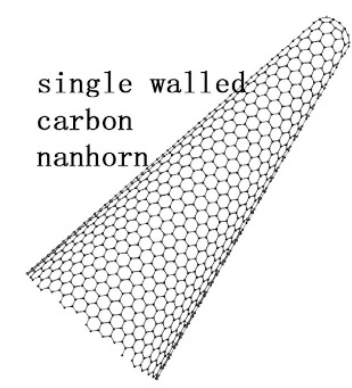

d

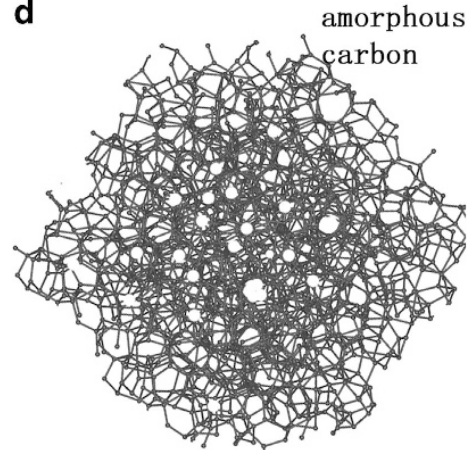

Figure 1 The structures of the four types of spherical nanocarbon materials discussed in this review: (a) fullerene, (b) carbon nanohorn, (c) nanodiamond and (d) amorphous carbon nanoparticle. Fullerenes form spherical nanoparticles tens of nanometers in size in aqueous solution. Carbon nanohorns produced by laser ablation or arc discharge also exist as robust spherical aggregates containing thousands of individual structures.

change the chemical and physical properties of fullerenes, increasing the functionality of these materials and making them useful in different applications. All of these structures will be referred to as fullerenes throughout this review.

Shortly after its discovery, it was proposed that $\mathrm{C}_{60}$ could inhibit the activity of human immunodeficiency virus (HIV) protease because $\mathrm{C}_{60}$ has the appropriate size to fit into the hydrophobic cavity of the enzyme. ${ }^{26,27}$ Since then, there have been many reports on the biological effects of fullerenes, including photodynamic therapy and magnetic resonance imaging (MRI) ${ }^{28}$ However, what is more interesting and widely investigated is the capability of fullerenes to act as 'radical sponges' in various schemes. ${ }^{29}$

\section{ROS-scavenging property of fullerenes}

Researchers have published contradictory reports on the radicalscavenging properties of pristine fullerenes (for example, $\mathrm{C}_{60}, \mathrm{C}_{70}$ ). Some studies have shown that pristine fullerenes produce reactive oxygen species (ROS), suggesting that fullerenes could be used in photodynamic therapy. Others have reported that in rats, $\mathrm{C}_{60}$ can prevent radical formation and liver and kidney damage caused by carbon tetrachloride. ${ }^{30,31}$ Meanwhile, it is recognized that fullerene derivatives possess a high capacity to intercept ROS and various radicals. ${ }^{32-36}$

As a versatile scavenger of ROS and free radicals, fullerene derivatives are reported to be promising as novel antioxidants in many important biological applications. ${ }^{37-39}$ For example, polyhydroxylated fullerene, $\mathrm{C}_{60}(\mathrm{OH})_{x}$, was found to have cellular protective properties, preventing neuronal cell damage and death from radicals generated from compounds such as 3morpholinosydnonimine and hydrogen peroxide. ${ }^{40,41} \mathrm{C}_{60}$ functionalized with 18 carboxylic groups has been shown to protect zebrafish embryos by scavenging the radicals that are formed by ionizing radiation. ${ }^{42}$ In another interesting study, tris-malonyl $\mathrm{C}_{60}$ was shown to penetrate the blood-brain barrier and suppress the mitochondrial damage caused by superoxide radicals. The mice treated with this fullerene compound had a longer life span and increased learning and memory capacity compared with untreated mice. $^{43}$

In addition, fullerene nanoparticles physically modified with surfactants, such as cyclodextrin or polymers, have shown ROSscavenging ability. In these cases, the fullerenes can be regarded as 'pristine' to some extent. $\mathrm{C}_{60}$ nanoparticles modified with sodium dodecyl sulfate, cyclodextrin or a co-polymer (that is, ethylene vinyl acetate-ethylene vinyl versatate) by mechanical milling were found to protect cells from nitric oxide-induced apoptosis. It was stated that the nanoparticles protected the nitric oxide-treated cells by neutralizing the superoxide radicals produced by the mitochondria. ${ }^{44}$ Colloidal $\mathrm{C}_{60}$-polymer complexes, such as poly $\mathrm{N}$-vinyl pyrrolidone or poly 2 alkyl-2-oxazoline, prepared by the so-called thin film hydration method also act as antioxidants against ultraviolet rays or superoxide radicals induced by angiotensin II in human skin keratinocytes and CATH.a neurons, respectively. ${ }^{45,46}$ These studies showed that pristine fullerenes, as well as fullerene derivatives, can also scavenge ROS in many cases.

ROS-scavenging capability of various fullerenes and their possible mechanisms of action

Although many fullerenes have been proven to intercept ROS, the extent of their scavenging ability depends largely on their structure and surface modifications. The ROS-scavenging capacities of three different types of water-soluble fullerenes (that is, $\mathrm{C}_{60}\left(\mathrm{C}(\mathrm{COOH})_{2}\right)_{2}$ (carboxyfullerene), $\mathrm{C}_{60}(\mathrm{OH})_{22}$ (fullerenol) and $\mathrm{Gd} @ \mathrm{C}_{82}(\mathrm{OH})_{22}$ ) were compared in a recent study. ${ }^{47}$ It was demonstrated that these fullerene derivatives reduce hydrogen peroxide-induced cytotoxicity, free radical formation and mitochondrial damage. For each system, the cell viability was evaluated and the intracellular ROS level was determined. It is concluded that the $\mathrm{Gd}_{0} @ \mathrm{C}_{82}(\mathrm{OH})_{22}$ nanoparticles exhibited the greatest cellular protective effects against hydrogen peroxide-induced cytotoxicity, followed by the fullerenol nanoparticles; the carboxyfullerene nanoparticles provided the least protection.

Oxidative stress is a major factor in many acute and chronic diseases. It can be triggered by ROS, mainly including superoxide radical anions $\left(\mathrm{O}_{2}{ }^{-}{ }^{-}\right)$, hydroxyl radicals $\left(\mathrm{HO}^{\circ}\right)$, singlet oxygen $\left({ }^{1} \mathrm{O}_{2}\right)$ and hydrogen peroxide species. ${ }^{48-50}$ As fullerenes have been shown to scavenge radicals, they may be valuable protective and therapeutic agents for many diseases. Thus, it is of the utmost importance to understand the molecular mechanism by which fullerenes scavenge ROS. The mechanism of $\mathrm{O}_{2}{ }^{-}{ }^{-}$quenching is similar to that of the quenching of superoxide dismutase. ${ }^{51-53}$ The radical easily binds to the electron-deficient area of the fullerene surface, resulting in electron transfer to the fullerene cage. Then, the binding of a second superoxide radical anion to an adjacent electron-deficient position induces the destruction of $\mathrm{O}_{2}{ }^{-}$, , production of hydrogen peroxide and regeneration of the original fullerene. In the initial step of the deactivation process, the singlet oxygen $\left({ }^{1} \mathrm{O}_{2}\right)$ associates to the fullerene and a charge-transfer complex is formed. ${ }^{54}$ The scavenging of more reactive radicals, such as $\mathrm{HO}$, is likely simpler from a mechanistic standpoint, involving stoichiometric addition of the radical to the electron-deficient surface of the fullerenes. ${ }^{55,56}$

It has been determined that cancer cells are under increased oxidative stress associated with higher levels of ROS. These higher 
ROS levels result in the stimulation of cellular proliferation, mutations and genetic instabilities. Thus, fullerenes, which can intercept ROS, may be extremely useful in biomedicine as cancer therapies as well as agents for helping to maintain general health. In recent studies, researchers found that $\mathrm{Gd}_{0} \mathrm{C}_{82}(\mathrm{OH})_{22}$ nanoparticles showed antineoplastic activity; these structures exhibited high efficiency and low toxicity (described in the next section).

\section{Antitumor effects and the indirect mechanism of action of $\mathrm{Gd} @ \mathrm{C}_{82}(\mathrm{OH})_{22}$ nanoparticles}

Early studies often employed endohedral metallofullerenes in biological applications as radiotracers or MRI contrast agents. ${ }^{57-61} \mathrm{~A}$ holmium-encapsulated water-soluble metallofullerene derivative was adopted as a tracer to investigate its in vivo biological behaviors and distribution. Studies using $\mathrm{Gd}_{0} \mathrm{C}_{82}(\mathrm{OH})_{x}$ mainly focused on application as a new generation of MRI contrast agents that were both highly efficient and low in toxicity. Recent work looking at the pharmaceutical effects of $\mathrm{Gd}_{0} \mathrm{C}_{82}(\mathrm{OH})_{x}$ revealed the antitumor properties of this popular fullerene material. ${ }^{62-64}$ The weights and volumes of tumors in tumor-bearing mice were reduced significantly when they were treated with a $\mathrm{Gd} @ \mathrm{C}_{82}(\mathrm{OH})_{22}$ solution. This solution exhibited a tumor-inhibitory capability comparable with that of one current clinical antineoplastic agent (CTX) taken at a much higher dosage (1000 times higher).

Researchers proposed a novel mechanism by which these Gd@ $\mathrm{C}_{82}(\mathrm{OH})_{22}$ nanoparticles acted against cancer, which may provide inspiration to others looking to design and construct novel antitumor pharmaceutical agents. The antitumor effect of a pharmaceutical is usually based on its ability to kill cancer cells, probably in a selective way. However, Gd@ $\mathrm{C}_{82}(\mathrm{OH})_{22}$ nanoparticles are not cytotoxic to certain cells, such as hepatomas and human breast cancer cells, implying that these nanoparticles likely do not kill cancer cells directly. ${ }^{62,65}$ In addition, a study of the biodistribution of $\mathrm{Gd} @ \mathrm{C}_{82}(\mathrm{OH})_{22}$ in vivo indicates that only a small amount of the administered dose reaches the tumor tissue. ${ }^{66}$ Therefore, these particles are thought to kill tumor cells via an 'indirect', rather than a direct, antitumor mechanism.

As described above, Gd@ $\mathrm{C}_{82}(\mathrm{OH})_{22}$ nanoparticles are outstanding antioxidants, and they can intercept various types of ROS to inhibit oxidative stress. Cancer cells are under increased oxidative stress compared with normal cells. ${ }^{67,68}$ Thus, $\mathrm{Gd} @ \mathrm{C}_{82}(\mathrm{OH})_{22}$ nanoparticles may improve the microenvironment of the neighboring cells, suppress the proliferation of cancer cells and prevent the mutation of surrounding normal cells by regulating the oxidative defense system.

In addition to their ROS-scavenging ability, $\mathrm{Gd}_{\mathrm{C}} \mathrm{C}_{82}(\mathrm{OH})_{22}$ nanoparticles show a strong capacity to improve immunity and interfere with a tumor's invasion into normal tissues in vivo. It was found that $\mathrm{Gd} @ \mathrm{C}_{82}(\mathrm{OH})_{22}$ nanoparticles function as strong immunomodulators, inducing the maturation of dendritic cells, which are important in the immune defense system, and activating Th1 immune responses. ${ }^{69}$ Additionally, strong immune responses were observed in the tumor tissues of $\mathrm{Gd}_{0} @ \mathrm{C}_{82}(\mathrm{OH})_{22}$ nanoparticle-treated tumor-bearing mice, but not in the control groups (Figure 2). ${ }^{62}$ Envelopes surrounding the neoplastic tissues, which are composed primarily of capillary vessels, fibroses and lymphadenoid tissues, were formed. These envelopes can suppress the growth and invasion of tumor cells.

In addition to preventing the transplantation of tumors by enveloping the invaded tumor cells, Gd@ $\mathrm{C}_{82}(\mathrm{OH})_{22}$ nanoparticles also prevent tumor metastasis by suppressing the expression and activity of key enzymes, matrix metalloproteinases (MMPs). ${ }^{70}$ The expression levels of MMP-2 and MMP-9 were found to be significantly lower in the $\mathrm{Gd}_{0} \mathrm{C}_{82}(\mathrm{OH})_{22}$ nanoparticle-treated tumor tissues of nude mice than those of the mice in the control groups; suppressed angiogenesis and inhibited tumor growth were also observed. Large-scale molecular-dynamic simulations suggest that $\mathrm{Gd} @ \mathrm{C}_{82}(\mathrm{OH})_{22}$ nanoparticles inhibit MMP-9 by indirectly interfering with incoming substrate by binding to critical regions, such as the ligand specificity loop $\mathrm{S1}^{\prime}$, instead of directly blocking the zinc-coordinated catalytic site (Figure 3 ). This mechanism of action differs from that of single-walled carbon nanotubes, which destroy the hydrophobic core and tertiary structure of the protein using strong hydrophobic and aromatic stacking interactions. ${ }^{71,72}$

Another biological effect of $\mathrm{Gd} @ \mathrm{C}_{82}(\mathrm{OH})_{22}$ nanoparticles is also noteworthy when considering to use it for antitumor therapies. Many chemotherapeutic agents kill cancer cells effectively, but because of their high toxicity and the susceptibility of cancer cells to develop resistance to them, successful treatment options are often limited. Gd@ $\mathrm{C}_{82}(\mathrm{OH})_{22}$ nanoparticles can reduce tumor resistance to cisplatin (a major chemotherapeutic agent) in vitro and in vivo. ${ }^{73}$ After pretreatment with these particles, the viability of cisplatin-resistive cancer cells was diminished and the growth of tumors was more effectively suppressed. It is known that tumors become resistant to cisplatin, partially because cisplatin uptake is reduced as a result of faulty formation of the endocytic recycling compartment. This result suggests that $\mathrm{Gd} @ \mathrm{C}_{82}(\mathrm{OH})_{22}$ nanoparticles can restore the endocytosis of cisplatin, reducing the drug resistance of the cells and enhancing the antitumor effect.

In conclusion, $\mathrm{Gd} @ \mathrm{C}_{82}(\mathrm{OH})_{22}$ nanoparticles are highly efficient, low toxicity antitumor agents, which function as antioxidants, enhance immunity, suppress metastasis and reduce drug resistance (Figure 4). They are incredibly useful antitumor therapies. However, the main challenge for developing these materials as novel nanomedicines in practical applications is their comparatively low synthetic yield. It is also costly and time-consuming to separate identical fullerene species from raw soot. Currently, people are developing large-scale production methods and facile separation processes to obtain high-purity fullerenes at low cost so that $\mathrm{Gd@C} \mathrm{C}_{82}(\mathrm{OH})_{22}$ nanoparticles can be used in clinical applications. ${ }^{74-76}$

\section{CARBON NANOHORNS FOR DRUG DELIVERY}

Single-wall carbon nanohorns (SWNHs) are another type of nanocarbon material that has the potential to be useful in nano-medicine. SWNH has a horn-tipped, tubular single-walled graphite structure and is between 2 and $5 \mathrm{~nm}$ in diameter and between 40 and $50 \mathrm{~nm}$ in length. Usually, thousands of SWNHs assemble to form a robust spherical aggregate with a narrow diameter between 80 and $100 \mathrm{~nm}$. Herein, we use the term 'SWNH aggregate' to refer to the assembled structure and 'SWNHs' to refer to the various forms of single-carbon nanohorns. SWNHs are produced by laser ablation without any metallic catalyst that is usually required to synthesize carbon nanotubes. This process can be used to produce high-purity SWNHs (>90\%) in high yield (at a lab scale of kilograms per day). Thus, enough material can be produced so that these structures could be used in practical applications. Moreover, they have a high surface area and effective volume; their surface area and effective volume can be further increased by introducing nano-sized holes in their side walls so that their internal spaces can also be accessed. These properties make SWNHs promising as supports in catalytic schemes, components in gas storage designs, fuel cells and lithium batteries, probes in biosensing and imaging approaches and agents for drug delivery. ${ }^{77-88}$ 

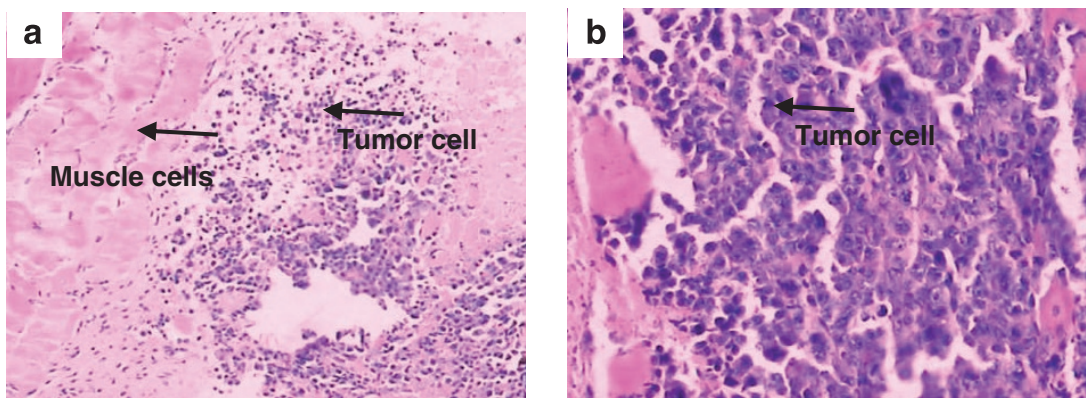

\section{Control}
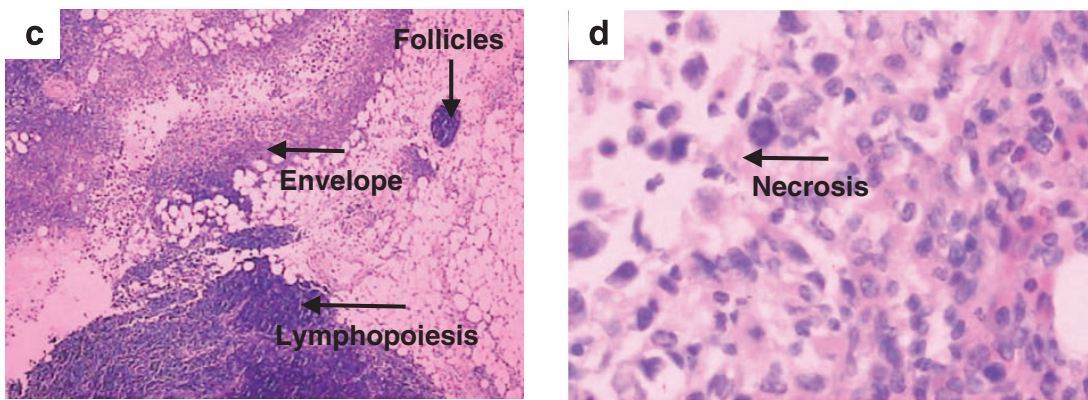

$\left[\mathrm{Gd} @ \mathrm{C}_{82}(\mathrm{OH})_{22}\right]_{\mathrm{n}}$
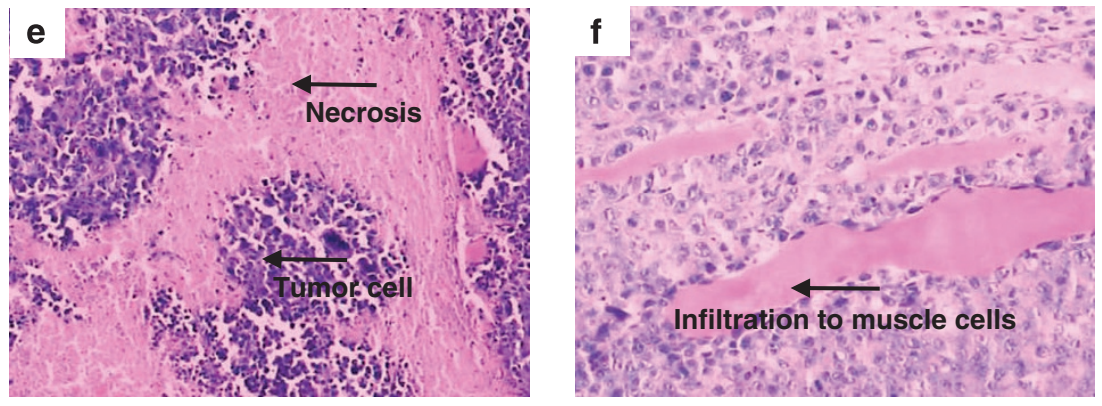

CTX

Figure 2 Hematoxylin and eosin (HE) staining of the tumor tissues from the control (a, b), Gd@ $\mathrm{C}_{82}(\mathrm{OH})_{22}$-treated (c, d), and CTX-treated (e and f) mice. Envelopes form around the tumor tissue, which is composed of lymphadenoid and fibrosis tissues associated with lymphopoiesis and aggregated (c, arrow) necroses of tumors (d), in the $\mathrm{Gd}_{0} \mathrm{C}_{82}(\mathrm{OH})_{22}$-treated group. Numerous necroses of tumor tissue (e) and visible tumor infiltration to muscle cells (f) are observed. (Original magnification: $\mathbf{a}, \mathbf{c}$ and $\mathbf{e} \times 40$; $\mathbf{b}$ and $\mathbf{d} \times 400, \mathbf{f} \times 200$ ). Reproduced with permission. Copyright 2005 from reference. ${ }^{62}$
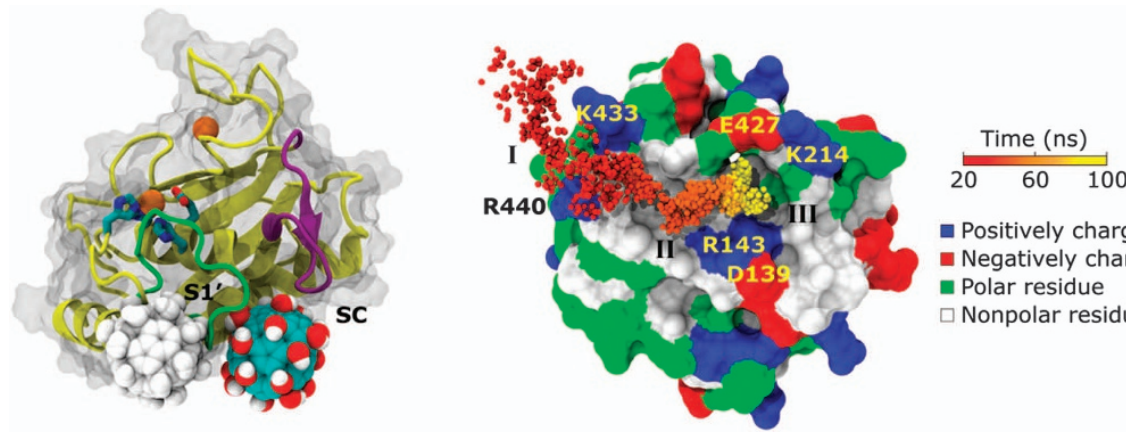

- Positively charged residue

Negatively charged residue

- Polar residue

$\square$ Nonpolar residue

Figure 3 Possible binding modes and binding pathway of $\mathrm{Gd}_{0} \mathrm{C}_{82}(\mathrm{OH})_{22}$ nanoparticles to MMP-9. (Left) Representative binding mode showing that $\mathrm{Gd}_{8} \mathrm{C}_{82}(\mathrm{OH})_{22}$ (a solid ball) binds between the S1' ligand-specificity loop (green ribbon) and the SC loop (purple ribbon), leading to the ligand binding groove. An alternative mode (with a gray ball) shows that $\mathrm{Gd}_{\mathrm{C}} \mathrm{C}_{82}(\mathrm{OH})_{22}$ can bind at the back entrance of the S1' cavity leading into the active site (ball and stick for active sites and orange ball for the catalytic $\mathrm{Zn}^{2+}$ ). (Right) Possible binding pathway, which depends on major driving forces and time (only the first $100 \mathrm{~ns}$ is shown). The binding dynamics are characterized by three different phases (I, II, III). See reference Kang et al. ${ }^{70}$ for more details. Reproduced with permission. Copyright 2012 from reference. ${ }^{70}$ 
The high surface area and abundant internal/interstitial spaces of SWNH aggregates are also excellent platforms for drug loading. For example, after incubation at room temperature overnight, dexamethasone (an anti-inflammatory and immunosuppressant) attached onto the hydrophobic surfaces of oxidized SWNH (SWNHox) aggregates. ${ }^{89}$ Cisplatin, a representative water-soluble small-molecule drug, can also be effectively deposited on and inside of SWNHox aggregates

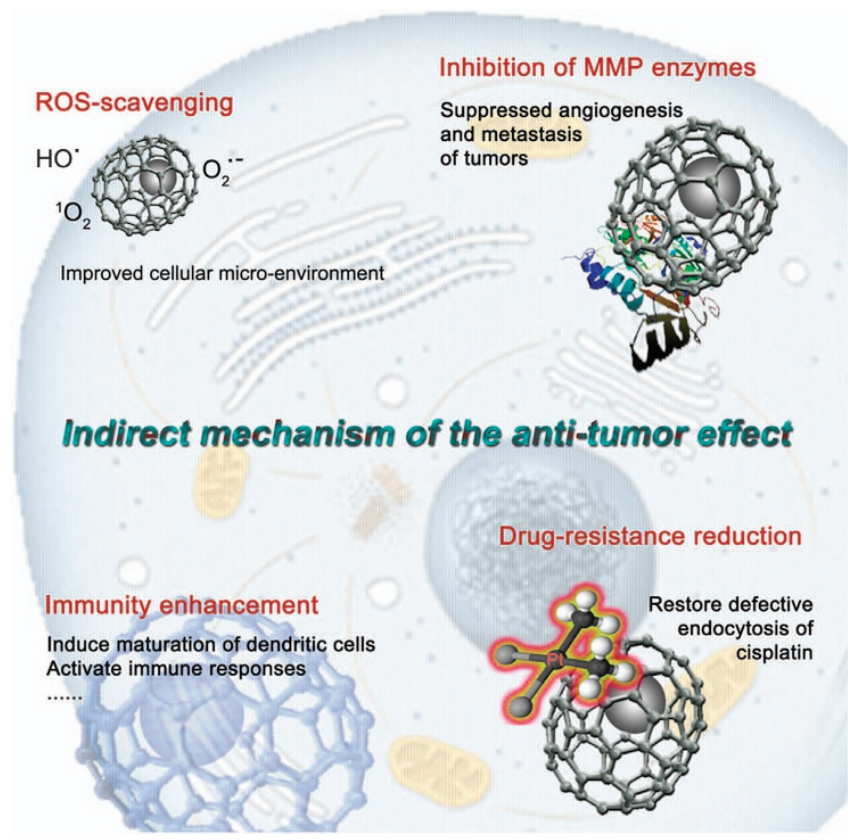

Figure 4 Illustration of the indirect mechanism of antitumor action of $\mathrm{Gd} @ \mathrm{C}_{82}(\mathrm{OH})_{22}$ nanoparticles.
(Figure 5). Further, it has been shown that when cisplatin was released from these aggregates, it remarkably reduces the viability of cancer cells. ${ }^{90}$ In another study, SWNH aggregates were used as a drug reservoir for the controlled release of vancomycin (an antibiotic agent). ${ }^{91}$ These early studies showed the potential of using SWNHs as nano-therapeutic drug carriers. In addition, the absence of metallic catalyst impurities in samples of pristine SWNHs eliminates this possible cause of toxicity. A recent toxicological assessment of SWNHs in which histological observations were made on mice tissues revealed that intravenously administered SWNHs did not cause obvious toxic responses after 26 weeks. ${ }^{92}$ Their outstanding drug-loading capacity and low toxicity make SWNHs a promising candidate for drug delivery applications. ${ }^{15,93}$

\section{Surface modifications for biocompatibility and multi- functionalization}

SWNHs have hydrophobic graphite surfaces. It is crucial to physically or chemically modify the surfaces of SWNHs with functional groups to increase their hydrophilicity, improve their biocompatibility, impart upon them a stealthy behavior and enable them to perform targeted delivery. The functional group most commonly used for this purpose is the carboxylic acid group, which can be introduced onto the surface by various oxidative processes. SWNHs have more defect sites and are more fragile than carbon nanotubes; they cannot survive treatment with strong acids. However, a softer oxidant, such as hydrogen peroxide, can be reacted with defect sites on SWNHs to generate carboxylic groups. ${ }^{94,95}$ The obtained SWNHox aggregates possess carboxylic groups at the edges of nano-sized holes in their structure. These groups could be used for further chemical reactions with other moieties, such as the protein bovine serum albumin (BSA). The obtained BAS-modified SWNH aggregates were well dispersed in phosphate-buffered saline and were efficiently taken up by mammalian cells through an endocytotic pathway. ${ }^{94}$
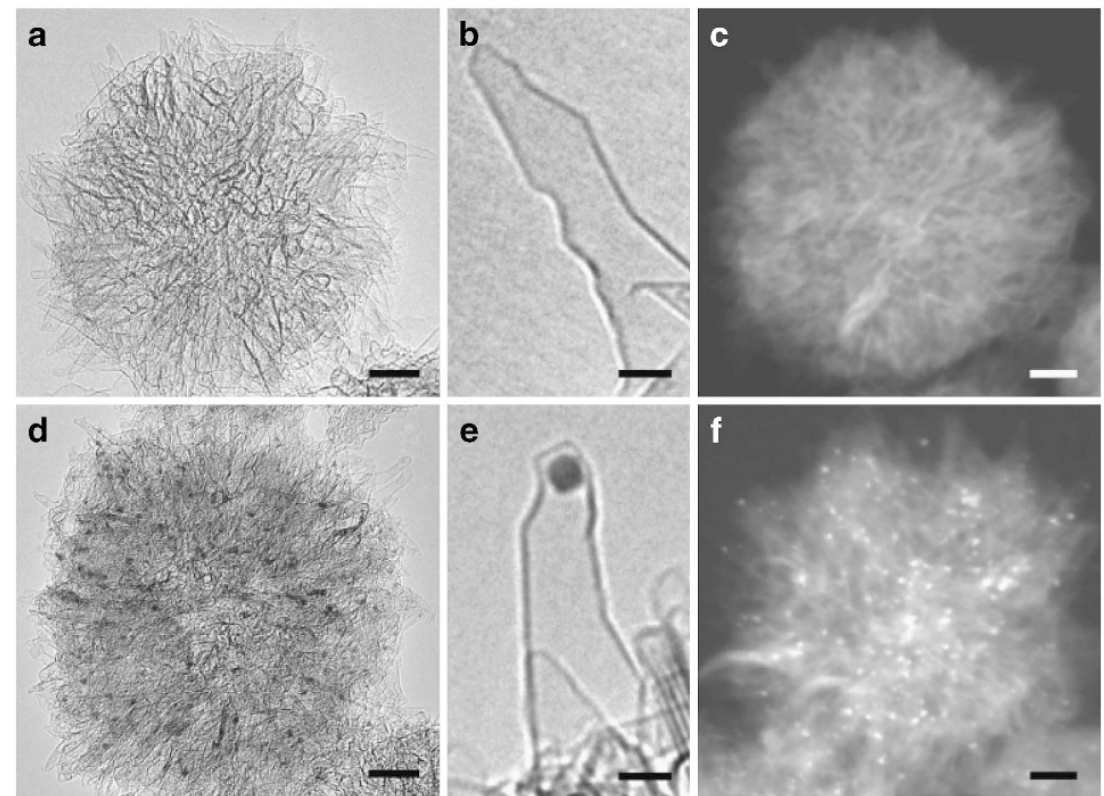

Figure 5 (a, b) HRTEM images of SWNHox (scale bar 10 and $2 \mathrm{~nm}$, respectively). (c) Z-contrast image of SWNHox aggregates (10 nm). (d, e) HRTEM images of cisplatin-loaded SWNHox aggregates (10 and $2 \mathrm{~nm}$, the black spots are cisplatin clusters). (f) Z-contrast image of cisplatin-loaded SWNHox aggregates (the bright spots are cisplatin clusters, $10 \mathrm{~nm}$ ). Reproduced with permission. Copyright 2005 from reference Ajima et al. ${ }^{90}$ 
Polyethylene glycol (PEG)-based amphiphilic molecules can be used to readily disperse hydrophobic materials in aqueous systems of high ionic strength and effectively prevent protein adsorption to their surfaces. Therefore, these molecules have been used to physically modify the surfaces of SWNHs, thereby reducing non-specific binding onto SWNH aggregates. ${ }^{96,97}$ Different types of PEG-based macromolecules showed different dispersion abilities with the SWNH aggregates. ${ }^{98}$ When PEG-doxorubicin was used to disperse SWNH aggregates, the as-obtained conjugates induced the apoptosis of cancer cells due to the anticancer pharmacodynamics of doxorubicin. $^{99}$ Cisplatin-loaded SWNH aggregates were also successfully modified with a dispersant comprising a peptide aptamer and a PEG chain. ${ }^{100}$ The dispersibility of the SWNH aggregates was further improved when a comb-shaped PEG branch was used, which resulted in a higher density of PEG chains covering the hydrophobic surface. ${ }^{101}$

\section{Antitumor effect of drug-loaded SWNH aggregates}

SWNH aggregates are versatile drug carriers that can be utilized to deliver various types of pharmaceutical agents, including hydrophilic and hydrophobic drug molecules with different molecular sizes and structures. For example, the anti-inflammatory agents vancomycin and prednisolone were both able to be adsorbed onto and inside of SWNH aggregates and released in a controlled manner. ${ }^{91,102}$ Antiinflammatory effects were observed in the tarsal joints of rats with collagen-induced arthritis after the direct injection of prednisoloneloaded SWNH aggregates.

More importantly, SWNH aggregates have been proven to be suitable platforms for carrying different types of anticancer drug molecules. The hydrophilic small-molecule drug cisplatin has been encapsulated by SWNH aggregates and shown to kill cancer cells upon its release. ${ }^{90}$ After the surface modification of cisplatinencapsulated SWNHs with conjugates composed of peptide aptamers and PEG chains, the nanostructures exhibited cancer suppression capabilities in mice. ${ }^{100,101}$ Some other hydrophobic molecules, such as dexamethasone and doxorubicin, were also deposited on SWNH aggregates, and the resulting conjugates showed antitumor capacity in vitro and in vivo. ${ }^{89,99,103} \mathrm{SWNH}$ aggregates also were able to carry macromolecules (polyamidoamine dendrimers) useful in gene therapy and release genetic material capable of diminishing the level of a protein directly involved in prostate cancer development. ${ }^{104}$

One exciting finding is that SWNH aggregates are able to function as a combined photodynamic and photohyperthermic agent when zinc phthalocyanine $(\mathrm{ZnPc})$ is incorporated in their structure. ${ }^{105}$ The protein bovine serum albumin (BSA) was used to disperse these materials and, in related cell experiments, ZnPc-loaded SWNHs suppressed the proliferation of the cancer cells when irradiation was also used; the cell viability also decreased (to $\sim 34 \%$ ). Meanwhile, the cell viability decreased to 59 or $68 \%$ when $\mathrm{ZnPc}$ alone or SWNHs without ZnPc, respectively, was used under the same irradiation conditions. Similar results were observed in tumor-bearing mice when 5RP7 cells were transplanted into both the left and right flanks. The results showed that without irradiation the tumors expanded quickly regardless of the substance injected into the tumors. In contrast, ZnPc-loaded SWNHs decreased the tumor volume markedly when laser irradiation was used. The tumor volumes of the control groups ( $\mathrm{ZnPc}$ and SWNHs without $\mathrm{ZnPc}$ ) were less suppressed even under irradiation (Figure 6).

The photodynamic effect of the ZnPc-loaded SWNHs was initialized by the charge separation state formed by electron transfer from a

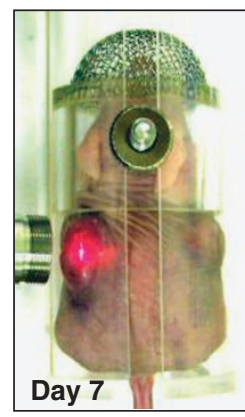

ZnPc-SWNHox-BSA

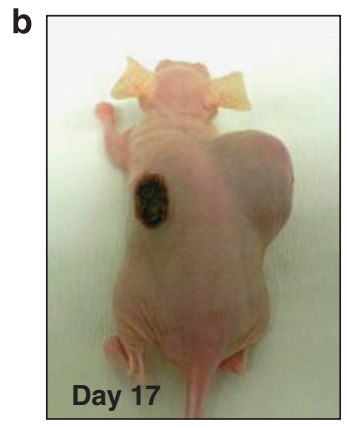

ZnPc-SWNHox-BSA
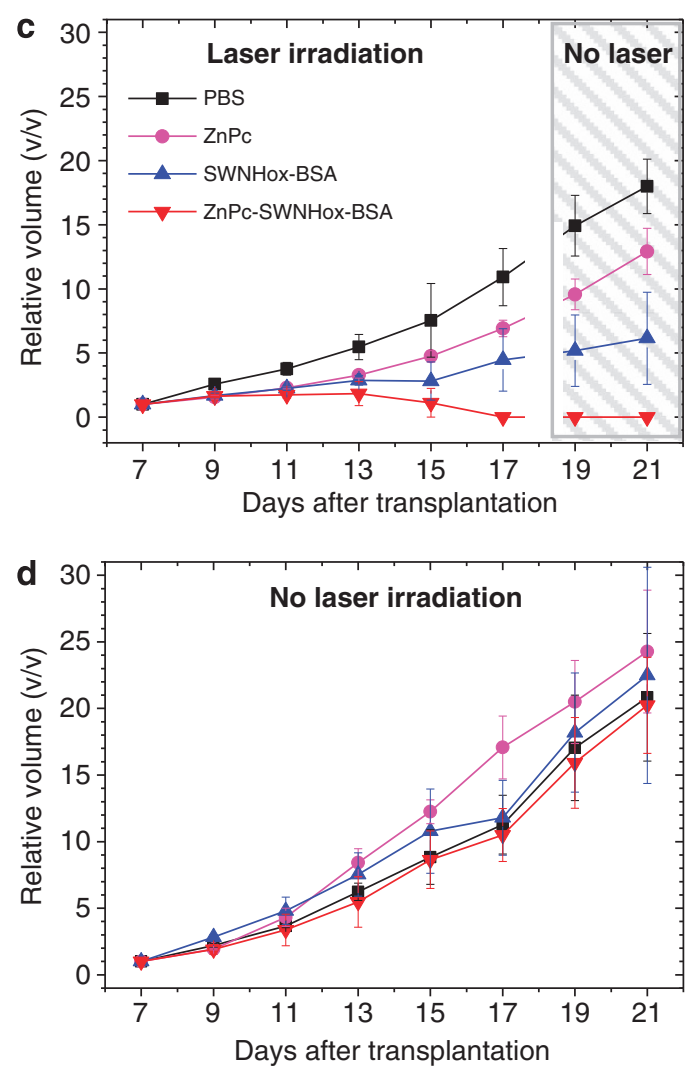

Figure 6 Photodynamic and hyperthermic destruction of tumors in vivo (a) A mouse with large tumors on its left and right flanks 7 days after tumor cell transplantation (day 7). The tumor on the left flank is being irradiated with a $670 \mathrm{~nm}$ laser. (b) A mouse after 10 days of treatment (day 17) with $\mathrm{ZnPc}-\mathrm{SWNHox}-\mathrm{BSA}$ and laser irradiation of the tumor on its left flank. (c) Relative volumes of tumors on the left flanks. Phosphate buffer saline (PBS, black line), PBS dispersions of ZnPc (magenta line), SWNHox-BSA (blue line), or ZnPc-SWNHox-BSA (red line) were intratumorally injected and treated with a $670 \mathrm{~nm}$ laser. (d) Relative volumes of tumors on the right flanks that were injected with PBS (black line), PBS dispersions of $\mathrm{ZnPc}$ (magenta line), SWNHox-BSA (blue line), or ZnPc-SWNHox-BSA (red line), but not subjected to laser irradiation. Reproduced with permission. Copyright 2008 from reference Zhang et al. ${ }^{105}$

the optically excited $\mathrm{ZnPc}$ to the SWNH. When the complex is excited, the nearby oxygen molecules can take electrons from the complex in the charge-separated state, generating ROS that can cause cancer cell death. The photohyperthermic effect of the SWNHs was also confirmed by monitoring the temperature of a solution of complexes in phosphate buffer saline. A similar temperature increase was observed when ZnPc-loaded SWNHs and SWNHs without ZnPc 
were irradiated, implying that the hyperthermic effect could be attributed to the SWNHs.

In conclusion, SWNHs are promising as versatile drug carriers in anticancer therapies due to their high surface area, abundant interior spaces and low toxicity. In addition to their high drug-loading capacity, SWNHs can be used to controllably release drugs by taking advantage of the possible limitation of nano-sized SWNH tubules and the interactions between adsorbed drug molecules and their surfaces. It is possible to construct multi-functional drug delivery systems that have increased blood circulation times, high accumulation ratios in tumor tissues and enhanced biocompatibility using the rich chemistry of the graphite surfaces of SWNHs. It is also likely that the size and shape of SWNH aggregates allow them to leak through the broken blood vessels of tumors and accumulate at a high local concentration (known as the enhanced permeability and retention (EPR) effect). ${ }^{106}$ Moreover, the photothermal properties of SWNHs allow them to be used in hyperthermia treatments in selective areas under long wavelength irradiation, which has a high tissue transmission ability. Owing to their unique structure and properties, SWNHs are outstanding candidate materials in several nanotherapeutic schemes. A major limitation to the use of SWNHs in practical biological applications is their high retention ratio; SWNHs do not easily degrade. ${ }^{107,108}$ Smaller sized SWNH aggregates, which can be obtained by adjusting the conditions of synthesis or applying postsynthetic separation techniques, could possibly be used to overcome these problems. ${ }^{109,110}$

\section{NANODIAMONDS AND POROUS CARBON NANOSPHERES FOR DRUG DELIVERY}

\section{Nanodiamonds for anticancer drug delivery}

Nanodiamonds were first produced decades ago, but they did not gain attention as novel agents for biological applications, such as drug delivery, biolabeling and sensing, until recently. ${ }^{16,17}$ As this review focuses on nano-therapeutic applications, we will only discuss studies that apply nanodiamonds for the cellular delivery of various therapeutic agents.

Nanodiamonds can be produced by detonation or other highpressure, high-temperature methods. After deagglomeration by mechanical milling or strong acid treatment, nano-scale diamond particles (as small as several nanometers in size) can be obtained. Owing to the harsh synthetic and post-synthetic conditions used, various oxygen-containing functional groups are present on the surface of diamond nanoparticles. The pristine diamond surface is less active as these oxygen-containing surface groups facilitate the surface modification of nanodiamonds primarily using dipole-dipole interactions, hydrogen bonding and covalent functionalization strategies. ${ }^{17}$ Many bioactive molecules, such as luciferase, cytochrome $c$ and protein lysozyme, can be immobilized onto the surface of nanodiamonds such that their chemical and biological activities are maintained. ${ }^{111-113}$

Different therapeutic agents have been attached onto activated nanodiamond surfaces and delivered into cells. Cisplatin, a widely used water-soluble chemotherapeutic agent, was attached to nanodiamonds and then released using $\mathrm{pH} .{ }^{114}$ The interaction between the cisplatin and the carboxyl groups on the nanodiamonds enabled its controlled release. On the other hand, several hydrophobic anticancer drugs were also loaded on the surface of nanodiamonds; the conjugates were able to be used in drug delivery, exhibiting an enhanced therapeutic efficiency. ${ }^{115}$ For example, a nanodiamonddoxorubicin conjugate was found to induce apoptosis in various cancer cell lines and suppress tumor growth in mouse models of liver and mammary cancer. ${ }^{116,117}$ By loading this drug on the nanodiamonds, its side effects were diminished and its release was delayed. In one very recent example, a multifunctional platform based on nanodiamonds was constructed, which could be used for selective targeting, imaging and therapy. ${ }^{118}$ The diamond nanoparticles were firstly functionalized with a crosslinker, sulfosuccinimidyl 6-(3'-[2pyridyldithio]propionamido)hexanoate, for the subsequent attachment of thiol-containing biomolecules. A chemotherapeutic, paclitaxel, was linked to a thiolated and fluorescently labeled oligonucleotide and a thiolated antibody was then coupled onto these structures. This conjugate showed an enhanced cellular internalization rate and therapeutic efficiency compared with paclitaxel alone.

In conclusion, nanodiamonds can be produced by different methods, possibly at an industrial scale. They can be used as multifunctional platforms to transport various types of bioactive molecules into cells. Moreover, it is possible to generate stable and bright fluorescent nanodiamonds that are useful in many biological processes by introducing nitrogen vacancies into their crystal lattice. ${ }^{119}$ The main challenge in using nanodiamonds in practical drug delivery applications is the isolation of uniform-sized nanoparticles with similar surface structure and charge during the deagglomeration step. Nanodiamonds are also limited in their drugloading capacity, and there are fewer ways in which their surface can be functionalized compared with the above-mentioned SWNHs and the porous carbon nanospheres, which are discussed below.

\section{Porous carbon nanospheres for drug delivery}

Carbon nanoparticles, here referring to various amorphous carbon nanoparticles and porous carbon nanospheres, are regarded as outstanding fluorescent nanomaterials that are able to be used for biological purposes such as biolabeling, imaging and sensing. ${ }^{21,120}$ However, there are few reports of their application in the cellular delivery of therapeutic agents. One recent report on this subject describes the use of hollow permeable carbon nanospheres (several hundred nanometers in size) that are coated in biodegradable polymer for the oral delivery of insulin. The polymer coating delays the release of insulin in acidic environments (for example, in the stomach), but sustained release can be achieved at near neutral conditions. ${ }^{121}$ In another example, 90-nm-sized mesoporous carbon nanospheres were used to deliver doxorubicin to HeLa cancer cells in a $\mathrm{pH}$-responsive way. ${ }^{122}$ The $\mathrm{pH}$ sensitivity was attributed to the different interactions between the carbon nanospheres and doxorubicin, which exists in both nonionized and ionized states. Thus, the drug may be able to remain inside the mesoporous carbon nanospheres at physiological $\mathrm{pH}$, but be efficiently released in the acidic environment of tumors.

Porous carbon nanospheres have the potential to be used as novel carriers for the cellular delivery of drugs due to their large surface areas and internal volumes. Moreover, the nano-sized pores in the outer shell of these nanoparticles can be harnessed to construct stimuli-responsive nano-valves. These valves could be used to controllably release drugs and enhance the therapeutic efficacy of treatments. However, there are still many questions that need to be addressed regarding how to control particle size and surface structure. The biocompatibility and toxicity of porous carbon nanospheres must also be assessed before they can be widely used as carriers.

\section{TOXICITY OF SPHERICAL NANOCARBON MATERIALS-ARE SPHERICAL NANOPARTICLES SAFER?}

Spherical nanocarbon materials, specifically fullerenes, SWNHs, nanodiamonds and carbon nanospheres, are promising as 
nanomedicines and antitumor therapies. However, to make therapeutic applications a reality, it is necessary to first assess the toxicity of these materials.

The toxicity of fullerenes is affected by a variety of parameters, including cage size and surface functionalization. There are conflicting reports concerning the toxicity of pristine $\mathrm{C}_{60}$, which can generate ROS and scavenge free radicals at the same time. Some studies have shown that pristine $\mathrm{C}_{60}$ causes cellular damage and is lethal to cells, while some people argue that it is a powerful antioxidant and exhibits no acute and subacute toxicity in vitro or in vivo. ${ }^{31,123}$ Many parameters, including the preparation method, the purity and surface modifications of the material and the degree of its agglomeration can significantly change the outcomes of toxicological studies. Additionally, the experimental protocols for each study differ. ${ }^{124,125}$ Therefore, it is difficult to make an absolute judgment on the toxicity of pristine $\mathrm{C}_{60}$ because the toxicity can be strongly dependent on the applied conditions (for example, light irradiation, impurity). In general, it is likely that $\mathrm{C}_{60}$ can function as an effective, relatively nontoxic pharmaceutical agent under certain conditions. Fullerenes typically cause little cytotoxicity or acute or subacute animal toxicity, especially after they are modified to be water soluble and biocompatible. For example, polyhydroxylated $\mathrm{C}_{60}$ was found to be markedly less toxic (several orders lower depending on the surface modification) than pristine $\mathrm{C}_{60} \cdot{ }^{126}$ The modified compound caused the formation of a small amount of hydrogen peroxide but not superoxide. Polyhydroxylated $\mathrm{C}_{60}$ did not induce oxidative stress (according to the assessment of cellular thiol levels) or the upregulation of protective antioxidant responses. ${ }^{127}$ After reviewing the toxicological studies of numerous fullerene derivatives, it was concluded that fullerenes in general show low toxicity (for example, acute oral, dermal, airway toxicity). ${ }^{128}$

$\mathrm{Gd} @ \mathrm{C}_{82}(\mathrm{OH})_{22}$ nanoparticles also are highly biocompatible in vitro and in vivo. ${ }^{62,65,66}$ Cell death was not induced when human (HepG2) and rat hepatoma cells $(\mathrm{RH} 35)$ were treated with $\mathrm{Gd} @ \mathrm{C}_{82}(\mathrm{OH})_{22}$ nanoparticles at different concentrations, indicating that this material is not cytotoxic. In in vivo studies of tumor-bearing mice, various biochemical parameters were monitored after treatment with $\mathrm{Gd} @ \mathrm{C}_{82}(\mathrm{OH})_{22}$ nanoparticles. The experimental results indicated that $\mathrm{Gd}_{0} \mathrm{C}_{82}(\mathrm{OH})_{22}$ nanoparticles efficiently stopped the deterioration of hapatocellular function caused by tumor cells in mice without causing further renal dysfunction after a successive injection for 20 days. Moreover, the histopathological examinations of the tissues and organs of the $\mathrm{Gd}_{0} \mathrm{C}_{82}(\mathrm{OH})_{22}$ nanoparticle-treated mice revealed that the liver, spleen, kidney, heart, brain and lung did not show abnormal pathological changes. Additionally, the potential toxicity of $\mathrm{Gd} @ \mathrm{C}_{82}(\mathrm{OH})_{22}$ nanoparticles were evaluated using a C. elegans model. The results showed that the nanoparticles were generally not toxic to C. elegans. The developmental process, pharyngeal pumping behavior and reproductive capabilities of C. elegans were not affected by treatment with $\mathrm{Gd}_{0} \mathrm{C}_{82}(\mathrm{OH})_{22}$ nanoparticles. $^{129}$ These results suggest that $\mathrm{Gd} @ \mathrm{C}_{82}(\mathrm{OH})_{22}$ nanoparticles have a very low toxicity in vivo.

The toxicities of pristine SWNHs and SWNHs with different surface modifications were examined in vitro and in vivo. In cell viability assessments, negligible cytotoxicity was observed for SWNHs with various surface modifications. ${ }^{23,90,93,94,99}$ In further animal tests, no abnormal body weight or clinical symptoms (including skin and eye irritation and lung tissue damage) were observed after the administration of SWNHs. ${ }^{92,130}$ Negative mutagenic and clastogenic results suggest that SWNHs are not carcinogenic. Moreover, histopathological examinations revealed that SWNHs were retained in the liver, lungs and spleen of the tested animals. ${ }^{92,107}$ Abnormal cellular degeneration and necrosis were not observed, indicating that SWNHs did not cause severe tissue damage. Histological abnormalities, such as granuloma and fibrosis, were not found; undesired inflammatory responses did not occur. All of these results suggest that SWNH have low toxicity both in vitro and in vivo.

Other spherical nanocarbon materials (that is, nanodiamonds and crystalline and amorphous carbon nanoparticles) were also reported to be low in toxicity, biocompatible and non-pathogenic. ${ }^{17,18,22,120,131}$ Several toxicological studies on nanodiamonds in vitro with various cell lines showed that they do not cause cytotoxic or detrimental effects on cellular proliferation. ${ }^{132,133}$ Through comprehensive bioassays, it was confirmed that nanodiamonds do not induce inflammation or the production of tumor necrosis factor alpha or inducible nitric oxide synthase in cells after incubation. ${ }^{117}$ Furthermore, by taking advantage of the intrinsic fluorescence of nanodiamonds, their biodistribution and biocompatibility were evaluated using a $C$. elegans and a mouse model. It was concluded that nanodiamonds with various surface modifications were nontoxic and highly biocompatible.

To summarize, representative spherical nanocarbon materials, such as fullerene nanoparticles, SWNH aggregates and nanodiamonds, are not acutely toxic in a time frame up to several months in length. Even different types of surface-modified materials showed little toxicity. Among the various surface modification methods, PEGylation is known to improve the biocompatibility of nanomaterials by enhancing their dispersion in biological fluids, reducing non-specific binding and inhibiting immune system recognition. This molecule also has been widely used to increase the dispersion and blood circulation times of liposomes and carbon nanotubes. ${ }^{10,24,134}$ PEGylated carbon nanotubes injected into the bloodstream of mice were shown to be nontoxic over a time period of 4 months, while pristine and oxidized carbon nanotubes were shown to affect mammalian embryonic development, causing extensive vascular lesions and increased ROS levels. ${ }^{135,136}$ Consistently, spherical nanocarbon materials functionalized with PEG have shown high biocompatibility. Of course, it is still necessary to perform more rigorous and detailed studies to uncover the mechanism and assess chronic toxicity and biodegradability, but these encouraging results are widely accepted by the scientific community (only a few contradictive reports exist) and reinforce the idea that these materials have the potential to be used in nanotherapeutic applications.

With this knowledge in hand, one can ask, 'Are spherical nanoparticles safer?' Some people believe that spherical nanoparticles are an excellent platform for biological applications because their simple geometry eliminates entanglement and ensures a consistent effective size and a comparatively uniform surface chemistry. Spherical nanoparticles, especially those $\sim 50 \mathrm{~nm}$ in size, are thought to be taken up by cells efficiently. In contrast, long multi-walled carbon nanotubes exhibit asbestos-like pathogenic behavior as a result of their rod-like shape and structure. ${ }^{137}$ The long, needle-like shape of carbon nanotubes cause inflammation and granulomas because some of them are too long to be completely engulfed by macrophages. ${ }^{138}$ It was also found that both single-walled and multi-walled carbon nanotubes adversely affected embryonic development. ${ }^{139,140}$ In a recent study using $C$. elegans as an animal model, acute toxicity, including retarded growth, shortened life span and defective embryogenesis, and accumulated chronic toxicity were observed. ${ }^{141}$ It is proposed that the geometry and agglomeration of carbon nanotubes, in addition to their metallic impurities, contribute to 
their toxicity. ${ }^{142}$ Still, we should be cautious to believe that spherical nanoparticles are always safer than tubular structures because the toxicological properties of nanomaterials are very complicated and depend on many different factors. Nonetheless, many current studies on spherical nanocarbon materials support the idea that the spherical shape may be advantageous in many biological systems.

\section{SUMMARY AND OUTLOOK}

One of the most interesting and important biological properties of fullerenes and fullerene derivatives is their ROS-scavenging capability. In addition to the many therapeutic applications that are based on this property, $\mathrm{Gd} @ \mathrm{C}_{82}(\mathrm{OH})_{22}$ nanoparticles present novel antitumor properties via an indirect mechanism that takes into account the ability of these structures to function as antioxidants, enhance immunity, suppress metastasis and reduce drug resistance.

SWNHs have the potential to act as highly efficient and lowtoxicity drug carriers in anticancer therapies. In addition to their high drug-loading capacity, SWNHs can be used to controllably release drugs by taking advantage of their high surface area and abundant internal and interstitial spaces. The photothermal behavior of SWNHs allows them to kill cancer cells in selective areas when they are irradiated by tissue-transparent, long wavelength light. Moreover, the nano-sized holes in SWNHox are possible active sites for the construction of nano-valves that could be used to control the release of the encapsulated drugs, including reversible dimers (for example, coumarin compounds) and anchored nanoparticles. These valves could be located on the edges of these nano-sized holes using the chemistry of the functional groups located there. ${ }^{143,144}$ A similar strategy can be applied to porous carbon nanospheres to control the rate of drug release at specific sites in response to external stimuli or tumor tissue microenvironment (tumors are more acidic and have a higher temperature than normal tissues).

Spherical nanocarbon materials have properties that make them promising as nano-medicines and therapeutic agents. The major limitations of realizing the practical applications of fullerenes are high cost and low production yield. It will be important to develop a largescale method for the synthesis and purification of these structures. The biggest challenge to the application of SWNHs is their high retention ratio and inability to degrade in biological systems. These issues may be overcome by adding appropriate surface modifications or decreasing the size of the SWNH aggregate by optimizing the conditions of synthesis or post-synthetic separation. Finally, it is vital to perform more rigorous and detailed long-term toxicological studies before using spherical nanocarbon materials in real biomedical applications.

\section{CONFLICT OF INTEREST}

The authors declare no conflict of interest.

\section{ACKNOWLEDGEMENTS}

This work was financially supported by the NSFC $(21277037,11305182)$ and the MOST 973 program (2012CB932504 and 2012CB932601).

1 Liu, Y. \& Wang, H. Nanomedicine: nanotechnology tackles tumours. Nat. Nanotechnol. 2, 20-21 (2007)

2 Shim, M. S. \& Kwon, Y. J. Stimuli-responsive polymers and nanomaterials for gene delivery and imaging applications. Adv. Drug Del. Rev. 64, 1046-1058 (2012).

3 Allen, T. M. \& Cullis, P. R. Drug delivery systems: entering the mainstream. Science 303, 1818-1822 (2004).

4 Krauss, T. D. Biosensors: nanotubes light up cells. Nat. Nanotechnol. 4, 85-86 (2009).
5 Jiang, H. J. Chemical preparation of graphene-based nanomaterials and their applications in chemical and biological sensors. Small 7, 2413-2427 (2011).

6 Jans, H. \& Huo, Q. Gold nanoparticle-enabled biological and chemical detection and analysis. Chem. Soc. Rev. 41, 2849-2866 (2012).

7 Swierczewska, M., Choi, K. Y., Mertz, E. L., Huang, X. L., Zhang, F., Zhu, L., Yoon, H. Y., Park, J. H., Bhirde, A., Lee, S. \& Chen, X. Y. A facile, one-step nanocarbon functionalization for biomedical applications. Nano Lett. 12, 3613-3620 (2012).

8 Kam, N. W. S., Jessop, T. C., Wender, P. A. \& Dai, H. Nanotube molecular transporters: internalization of carbon nanotube - protein conjugates into mammalian cells. J. Am. Chem. Soc. 126, 6850-6851 (2004).

9 Chen, Z., Tabakman, S. M., Goodwin, A. P., Kattah, M. G., Daranciang, D., Wang, X., Zhang, G., Li, X., Liu, Z., Utz, P. J., Jiang, K., Fan, S. \& Dai, H. Protein microarrays with carbon nanotubes as multicolor Raman labels. Nat. Biotechnol. 26, 1285-1292 (2008).

10 Liu, Z., Davis, C., Cai, W., He, L., Chen, X. \& Dai, H. Circulation and long-term fate of functionalized, biocompatible single-walled carbon nanotubes in mice probed by Raman spectroscopy. Proc. Natl Acad. Sci. USA 105, 1410-1415 (2008).

11 Valentini, F., Carbone, M. \& Palleschi, G. Carbon nanostructured materials for applications in nano-medicine, cultural heritage, and electrochemical biosensors. Anal. Bioanal. Chem. 405, 451-465 (2013).

12 Kostarelos, K., Bianco, A. \& Prato, M. Promises, facts and challenges for carbon nanotubes in imaging and therapeutics. Nat. Nanotechnol. 4, 627-633 (2009).

13 Maeda-Mamiya, R., Noiri, E., Isobe, H., Nakanishi, W., Okamoto, K., Doi, K., Sugaya, T., Izumi, T., Homma, T. \& Nakamura, E. In vivo gene delivery by cationic tetraamino fullerene. Proc. Natl Acad. Sci. USA 107, 5339-5344 (2010).

14 Nakamura, E. \& Isobe, H. In vitro and in vivo gene delivery with tailor-designed aminofullerenes. Chem. Rec. 10, 260-270 (2010).

15 Yamashita, T., Yamashita, K., Nabeshi, H., Yoshikawa, T., Yoshioka, Y., Tsunoda, S. \& Tsutsumi, Y. Carbon nanomaterials: efficacy and safety for nanomedicine. Mater. 5, 350-363 (2012).

16 Chao, J., Perevedentseva, E., Chung, P., Liu, K., Cheng, C., Chang, C. \& Cheng, C. Nanometer-sized diamond particle as probe for biolabeling. Biophys. J. 93, 2199-2208 (2007)

17 Krueger, A. New carbon materials: biological applications of funtionalized nanodiamond materials. Chem. Eur. J. 14, 1382-1390 (2008).

18 Man, H. B. \& Ho, D. Diamond as a nanomedical agent for versatile applications in drug delivery, imaging, and sensing. Phys. Status Solidi. A 209, 1609-1618 (2012).

19 Tang L. A. L., Lee, W. C. Shi, H., Wong, E. Y. L. Sadovoy, A Gorelik, S., Hobley, J., Lim, C. T. \& Loh, K. P. Highly wrinkled cross-linked graphene oxide membranes for biological and charge-storage applications. Small 8, 423-431 (2012).

20 Dong, H. Q., Li, Y. Y., Yu, J. H., Song, Y. Y., Cai, X. J., Liu, J. Q., Zhang, J. M., Ewing, R. C. \& Shi, D. L. A versatile multicomponent assembly via -cyclodextrin hostguest chemistry on graphene for biomedical applications. Small 9, 446-456 (2013).

21 Posthuma-Trumpie, G. A., Wichers, J. H., Koets, M., Berendsen, L. \& Amerongen, A. Amorphous carbon nanoparticles: a versatile label for rapid diagnostic (immuno)assays. Anal. Bioanal. Chem. 402, 593-600 (2012).

22 Yan, A., Lau, B. W., Weissman, B. S., Kulaots, I., Yang, N. Y. C., Kane, A. B. \& Hurt, R. H. Biocompatible, hydrophilic supramolecular carbon nanoparticles for cell delivery. Adv. Mater. 18, 2373-2378 (2006).

23 Bianco, A., Kostarelos, K. \& Prato, M. Opportunities and challenges of carbon-based nanomaterials for cancer therapy. Expert Opin. Drug. Deliv. 5, 331-342 (2008)

24 Fisher, C., Rider, A. E., Han, Z. J., Kumar, S., Levchenko, I. \& Ostrikov, K. Applications and nanotoxicity of carbon nanotubes and graphene in biomedicine J. Nanomater. 2012, 315185 (2012).

25 Shinohara, H. Endohedral metallofullerenes. Rep. Prog. Phys. 63, 843-892 (2000).

26 Friedman, S. H., DeCamp, D. L., Sijbesma, R. P., Srdanov, G., Wudl, F. \& Kenyon, G. L. Inhibition of the HIV- 1 protease by fullerene derivatives: model building studies and experimental verification. J. Am. Chem. Soc. 115, 6506-6509 (1993).

27 Sijbesma, R. P., Srdanov, G., Wudl, F., Castoro, J. A., Wilkins, C., Friedman, S. H., DeCamp, D. L. \& Kenyon, G. L. Synthesis of a fullerene derivative for the inhibition of HIV enzymes. J. Am. Chem. Soc. 115, 6510-6512 (1993).

28 Partha, R. \& Conyers, J. L. Biomedical applications of functionalized fullerene-based nanomaterials. Int/. J. Nanomed. 4, 261-275 (2009).

29 Xiao, L., Takada, H., Gan, X. \& Miwa, N. The water-soluble fullerene derivative 'Radical Sponge' exerts cytoprotective action against UVA irradiation but not visiblelight-catalyzed cytotoxicity in human skin keratinocytes. Bioorg. Med. Chem. Lett. 16, 1590-1595 (2006)

30 Sayes, C. M., Gobin, A. M., Ausman, K. D., Mendes, J., West, J. L. \& Colvin, V. L. NanoC60 cytotoxicity is due to lipid peroxidation. Biomaterial 26, 7587-7595 (2005).

31 Gharbi, N., Pressac, M., Hadchouel, M., Szwarc, H., Wilson, S. R. \& Moussa, F. [60]fullerene is a powerful antioxidant in vivo with no acute or subacute toxicity. Nano Lett. 5, 2578-2585 (2005).

32 Jensen, A. W., Wilson, S. R. \& Schuster, D. I. Biological applications of fullerenes. Bioorg. Med. Chem. 4, 767-779 (1996).

33 Wilson, L. J. Medical applications of fullerenes and metallofullerenes. Electrochem. Soc. Interface 8, 24-28 (1999).

34 Tsai, M. C., Chen, Y. H. \& Chiang, L. Y. Polyhydroxylated C60, fullerenol, a novel freeradical trapper, prevented hydrogen peroxide- and cumene hydroperoxide-elicited changes in rat hippocampus in-vitro. J. Pharm. Pharmacol. 49, 438-445 (1997).

35 Bisaglia, M., Natalini, B., Pellicciari, R., Straface, E., Malorni, W., Monti, D., Franceschi, C. \& Schettini, G. C3-fullero-tris-methanodicarboxylic acid protects cerebellar granule cells from apoptosis. J. Neurochem. 74, 1197-1204 (2000).

36 Lai, H. S., Chen, W. J. \& Chiang, L. Y. Free radical scavenging activity of fullerenol on the Ischemia-reperfusion intestine in dogs. World J. Surg. 24, 450-454 (2000). 
37 Jain, K. K. The role of nanobiotechnology in drug discovery. Drug Discov. Today 10, 1435-1442 (2005)

38 Satoh, M. \& Takayanag, I. Pharmacological studies on fullerene (C60), a novel carbon allotrope, and its derivatives. J. Pharmacol. Sci. 100, 513-518 (2006).

39 Djordjevic, A., Bogdanovic, G. \& Dobric, S. Fullerenes in biomedicine. J. BUON. 11, 391-404 (2006).

40 Isakovic, A., Markovic, Z., TOdorovic-Markovic, B., Nikolic, N., Vranjes-Djuric, S., Mirkovic, M., Dramicanin, M., Harhaji, L., Raicevic, N., Nikolic, Z. \& Trajkovic, V. Distinct cytotoxic mechanisms of pristine versus hydroxylated fullerene. Toxicol. Sci. 91, 173-183 (2006).

41 Dugan, L. L., Gabrielsen, J. K., Yu, S. P., Lin, T. S. \& Choi, D. W. Buckminsterfullerenol free radical scavengers reduce excitotoxic and apoptotic death of cultured cortical neurons. Neurobiol. Dis. 3, 129-135 (1996).

42 Daroczi, B., Kari, G., McAleer, M. F., Wolf, J. C., Rodeck, U. \& Dicker, A. P. In vivo radioprotection by the fullerene nanoparticle DF-1 as assessed in a zebrafish model. Clin. Cancer Res. 12, 7086-7091 (2006).

43 Quick, K. L., Ali, S. S., Arch, R., Xiong, C., Wonzniak, D. \& Dugan, L. L. A carboxyfullerene SOD mimetic improves cognition and extends the lifespan of mice. Neurobiol. Aging 29, 117-128 (2008).

44 Misirkic, M. S., Todorovic-Markovic, B. M., Vucicevic, L. M., Janjetovic, K. D. Jokanovic, V. R., Dramicanin, M. D., Markovic, Z. M. \& Trajkovic, V. S. The protection of cells from nitric oxide-mediated apoptotic death by mechanochemically synthesized fullerene (C(60)) nanoparticles. Biomaterial 30, 2319-2328 (2009).

45 Xiao, L., Takada, H., Maeda, K., Haramoto, M. \& Miwa, N. Antioxidant effects of water-soluble fullerene derivatives against ultraviolet ray or peroxylipid through thei action of scavenging the reactive oxygen species in human skin keratinocytes. Biomed. Pharmacother. 59, 351-358 (2005).

46 Tong, J., Zimmerman, M. C., Li, S. M., Yi, X., Luxenhofer, R., Jordan, R. \& Kabanov, A. V. Neuronal uptake and intracellular superoxide scavenging of a fullerene (C60)-poly(2-oxazoline)s nanoformulation. Biomaterial 32, 3654-3665 (2011).

47 Yin, J. J., Lao, F., Fu, P. P., Wamer, W. G., Zhao, Y. L., Wang, P. C., Qiu, Y., Sun, B. Y., Xing, G. M., Dong, J. Q., Liang, X. J. \& Chen, C. Y. The scavenging of reactive oxygen species and the potential for cell protection by functionalized fullerene materials. Biomaterial 30, 611-621 (2009).

48 Aust, S. D., Chignell, C. F., Bray, T. M., Kalyanaraman, B. \& Mason, R. P. Free radicals in toxicology. Toxicol. Appl. Pharmacol. 120, 168-178 (1993).

49 Loft, S. \& Poulsen, H. E. Cancer risk and oxidative DNA damage in man. J. Mol. Med. 74, 297-312 (1996).

50 Stadtman, E. R. \& Berlett, B. S. Reactive oxygen-mediated protein oxidation in aging and disease. Chem. Res. Toxicol. 10, 485-494 (1997).

51 Chiang, L. Y., Lu, F. J. \& Lin, J. T. Free-radical scavenging activity of water-soluble fullerenols. J. Chem. Soc. Chem. Commun. 1283-1284 (1995).

52 Ali, S. S., Hardt, J. I., Quick, K. L., Kim-Han, J. S., Erlanger, B. F., Huang, T. T., Epstein, C. J. \& Dugan, L. L. A biologically effective fullerene (C60) derivative with superoxide dismutase mimetic properties. Free Radic. Biol. Med. 37, 1191-1202 (2004).

53 Osuna, S., Swart, M. \& Sola, M. On the mechanism of action of fullerene derivatives in superoxide dismutation. Chem. Eur. J. 16, 3207-3214 (2010).

54 Kopylov, V. B. \& Gavronskaya, Y. Y. Electronic and vibrational spectra of fullerenes in contact with oxygen. Russian J. Gen. Chem. 71, 1589-1592 (2001).

55 Bensasson, R. V., Brettreich, M., Frederiksen, J., Gottinger, H., Hirsch, A., Land, E. J., Leach, S., McGarvey, D. J. \& Schonberger, H. Reactions of e(-)(aq), $\mathrm{CO}(2)\left({ }^{*}\right)(-), \mathrm{HO}\left(^{*}\right)$, $\mathrm{O}(2)\left({ }^{*}\right)(-)$ and $\mathrm{O}(2)((1)$ delta(g)) with a dendro[60]fullerene and $\mathrm{C}(60)[\mathrm{C}(\mathrm{COOH})(2)](\mathrm{n})$ $(n=2-6)$. Free Radical. Bio. Med. 29, 26-33 (2000).

56 Krusic, P. J., Wasserman, E., Keizer, P. N., Morton, J. R. \& Preston, K. F. Radical reactions of c60. Science 254, 1183-1185 (1991).

57 Simonin, J. P. Solvent effects on osmotic second virial coefficient studied using analytic molecular models. Application to solutions of C60 fullerene. J. Phys. Chem. B 105, 5262-5270 (2001).

58 Cagle, D. W., Kennel, S. J., Mirzadeh, S., Michael Alford, J. \& Wilson, L. J. In vivo studies of fullerene-based materials using endohedral metallofullerene radiotracers. Proc. Natl Acad. Sci. USA 96, 5182-5187 (1999).

59 Okumura, M., Mikawa, M., Yokawa, T., Kanazawa, Y., Kato, H. \& Shinohara, H. Evaluation of water-soluble metallofullerenes as MRI contrast agents. Acad. Radiol. 9, S495-S497 (2002).

60 Mikawa, M., Kato, H., Okumura, M., Narazaki, M., Kanazawa, Y., Miwa, N. \& Shinohara, H. Paramagnetic water-soluble metallofullerenes having the highest relaxivity for MRI contrast agents. Bioconjug. Chem. 12, 510-514 (2001).

61 Bolskar, R. D., Benedetoo, A. F., Husebo, L. O., Price, R. E., Jackson, E. F., Wallace, S. \& Wilson, L. J. First soluble M@C60 derivatives provide enhanced access to metallofullerenes and permit in vivo evaluation of $\mathrm{Gd@C6O[C(COOH)2]10} \mathrm{as} \mathrm{a}$ MRI contrast agent. J. Am. Chem. Soc. 125, 5471-5478 (2003).

62 Chen, C. Y., Xing, G. M., Wang, J. X., Zhao, Y. L., Li, B., Tang, J., Jia, G., Wang, T. C., Sun, J., Xing, L., Yuan, H., Gao, Y. X., Meng, H., Chen, Z., Zhao, F., Chai, Z. F. \& Fang, X. H. Multihydroxylated [Gd@C82(OH)22]n nanoparticles: antineoplastic activity of high efficiency and low toxicity. Nano Lett. 5, 2050-2057 (2005).

63 Yin, J. J., Lao, F., Meng, J., Fu, P. P., Zhao, Y. L., Xing, G. M., Gao, X. Y., Sun, B. Y. Wang, P. C., Chen, C. Y. \& Liang, X. J. Inhibition of tumor growth by endohedral metallofullerenol nanoparticles optimized as reactive oxygen species scavenger. Mol. Pharmacol. 74, 1132-1140 (2008)

64 Wang, J., Gu, F., Ding, T., Liu, X. L., Xing, G. M., Zhao, Y. L., Zhang, N. \& Ma, Y. J. [Gd@C82(OH)22]n nanoparticles inhibit the migration and adhesion of glioblastoma cells. Oncol. Lett. 1, 771-775 (2010).
65 Meng, J., Xing, M., Wang, Y. Z., Lu, J., Zhao, Y. L., Gao, X. Y., Wang, P. C., Jia, L. \& Liang, X. J. Epigenetic modulation of human breast cancer by metallofullereno nanoparticles: in vivo treatment and in vitro analysis. Nanoscale 3, 4713-4719 (2011).

66 Wang, J. X., Chen, C. Y., Li, B., Yu, H. W., Zhao, Y. L., Sun, J., Li, Y. F., Xing, G. M., Yuan, H., Tang, J., Chen, Z., Meng, H., Gao, Y. X., Ye, C., Chai, Z. F., Zhu, C. F. Ma, B. C., Fang, X. H. \& Wan, L. J. Antioxidative function and biodistribution of [Gd@C82(OH)22]n nanoparticles in tumor-bearing mice. Biochem. Pharmacol. 71, 872-881 (2006).

67 Toyokuni, S., Okamoto, K., Yodoi, J. \& Hiai, H. Persistent oxidative stress in cancer. Febs. Lett. 358, 1-3 (1995).

68 Pelicano, H., Carney, D. \& Huang, P. ROS stress in cancer cells and therapeutic implications. Drug Resist. Updat. 7, 97-110 (2004).

69 Yang, D., Zhao, Y. L., Guo, H., Li, Y. N., Tewary, P., Xing, G. M., Hou, W. Oppenheim, J. J. \& Zhang, N. [Gd@C82(OH)22]n nanoparticles induce dendritic cell maturation and activate Th1 immune responses. Acs Nano 4, 1178-1186 (2010).

70 Kang, S., Zhou, G. Q., Yang, P., Liu, Y., Sun, B. Y., Huynh, T., Meng, H., Zhao, L. N., Xing, G. M., Chen, C. Y., Zhao, Y. L. \& Zhou, R. H. Molecular mechanism of pancreatic tumor metastasis inhibition by Gd@C82(OH)22 and its implication for de novo design of nanomedicine. Proc. Natl Acad. Sci. USA 109, 15431-15436 (2012).

71 Zuo, G., Huang, Q., Wei, G., Zhou, R. \& Fang, H. Plugging into proteins: poisoning protein function by a hydrophobic nanoparticle. ACS Nano 4, 7508-7514 (2010).

72 Ge, C. C., Du, J. F., Zhao, L. N., Wang, L. M., Liu, Y., Li, D. H., Yang, Y. L., Zhou, R. H., Zhao, Y. L., Chai, Z. F. \& Chen, C. Y. Binding of blood proteins to carbon nanotubes reduces cytotoxicity. Proc. Natl Acad. Sci. USA 108, 16968-16973 (2011).

73 Liang, X. J., Meng, H., Wang, Y. Z., He, H. Y., Meng, J., Lu, J., Wang, P. C., Zhao, Y. L., Gao, X. Y., Sun, B. Y., Chen, C. Y., Xing, G. M., Shen, D. W., Gottesman, M. M., Wu, Y., Yin, J. J. \& Jia, L. Metallofullerene nanoparticles circumvent tumor resistance to cisplatin by reactivating endocytosis. Proc. Natl Acad. Sci. USA 107 7449-7454 (2010).

74 Li, J., Zhang, M. Y., Sun, B. Y., Xing, G. M., Song, Y., Guo, H. L., Chang, Y., Ge, Y. H. \& Zhao, Y. L. Separation and purification of fullerenols for improved biocompatibility. Carbon. NY 50, 460-469 (2011).

75 Raebiger, J. W. \& Bolskar, R. D. Improved production and separation process for gadolinium metallofullerenes. J. Phys. Chem. C 112, 6605-6612 (2008).

76 Akiyama, K., Hamano, T., Nakanishi, Y., Takeuchi, E., Noda, S., Wang, Z. Y., Kubuki, S. \& Shinohara, H. Non-HPLC rapid separation of metallofullerenes and empty cages with TiCl4 Lewis acid. J. Am. Chem. Soc. 134, 9762-9767 (2012).

77 Pagona, G., Mountrichas, G., Rotas, G., Karousis, N., Pispas, S. \& Tagmatarchis, N. Properties, applications and functionalization of carbon nanohorns. Int. J. Nanotechnol. 6, 176-195 (2009).

78 Brandao, L., Passeira, C., Gattia, D. M. \& Mendes, A. Use of single wall carbon nanohorns in polymeric electrolyte fuel cells. J. Mater. Sci. 46, 7198-7205 (2011).

79 Izadi-Najafabadi, A., Yamada, T., Futaba, D. N., Yudasaka, M., Takagi, H., Hatori, H. lijima, S. \& Hata, K. High-power supercapacitor electrodes from single-walled carbon nanohorn/nanotube composite. Acs Nano 5, 811-819 (2011).

80 Zhao, Y., Li, J. X., Ding, Y. H. \& Guan, L. H. Single-walled carbon nanohorns coated with $\mathrm{Fe} 2 \mathrm{O} 3$ as a superior anode material for lithium ion batteries. Chem. Commun. 47, 7416-7418 (2011).

81 Zhu, S. Y., Liu, Z. Y., Zhang, W., Han, S., Hu, L. Z. \& Xu, G. B. Nucleic acid detection using single-walled carbon nanohorns as a fluorescent sensing platform. Chem. Commun. 47, 6099-6101 (2011).

82 Li, J., He, Y. J., He, Z., Zeng, P. \& Xu, S. K. Synthesis of NaYF4:Yb,Er/single-walled carbon nanohorns nanocomposite and its application as cells label. Anal. Biochem. 428, 4-6 (2012).

83 Liu, Y., Brown, C. M., Neumann, D. A., Geohegan, D. B., Puretzky, A. A., Rouleau, C. M., Hu, H., Styers-Barnett, D., Krasnov, P. O. \& Yakobson, B. I. Metal-assisted hydrogen storage on Pt-decorated single-walled carbon nanohorns. Carbon. NY 50, 4953-4964 (2012).

84 Niu, B., Xu, W., Guo, Z. D., Zhou, N. Z., Liu, Y., Shi, Z. J. \& Lian, Y. F. Controllable deposition of platinum nanoparticles on single-wall carbon nanohorns as catalyst for direct methanol fuel cells. J. Nanosci. Nanotechnol. 12, 7376-7381 (2012).

85 Pagona, G., Zervaki, G. E., Sandanayaka, A. S. D., Ito, O., Charalambidis, G., Hasobe, T., Coutsoleos, A. G. \& Tagmatarchis, N. Carbon nanohorn-porphyrin dimer hybrid material for enhancing light-energy conversion. J. Phys. Chem. C 116, 9439-9449 (2012).

86 Yuge, R., Manako, T., Nakahara, K., Yasui, M., Iwasa, S. \& Yoshitake, T. The production of an electrochemical capacitor electrode using holey single-wall carbon nanohorns with high specific surface area. Carbon NY 50, 5569-5573 (2012).

87 Zhang, L. W., Zheng, N., Gao, A., Zhu, C. M., Wang, Z. Y., Wang, Y., Shi, Z. J. \& Liu, Y. A robust fuel cell cathode catalyst assembled with nitrogen-doped carbon nanohorn and platinum nanoclusters. J. Power Sources 220, 449-454 (2012).

88 Zhu, S. Y., Liu, Z. Y., Hu, L. Z., Yuan, Y. L. \& Xu, G. B. Turn-on fluorescence sensor based on single-walled-carbon-nanohorn-peptide complex for the detection of thrombin. Chem. Eur. J. 18, 16556-16561 (2012).

89 Muralkami, T., Ajima, K., Miyawaki, J., Yudasaka, M., lijima, S. \& Shiba, K. Drug-loaded carbon nanohorns: adsorption and release of dexamethasone in vitro. Mol. Pharmaceut. 1, 399-405 (2004).

90 Ajima, K., Yudasaka, M., Murakami, T., Maigne, A., Shiba, K. \& Ijima, S. Carbon nanohorns as anticancer drug carriers. Mol. Pharmaceut. 2, 475-480 (2005).

91 Xu, J. X., Yudasaka, M., Kouraba, S., Sekido, M., Yamamoto, Y. \& lijima, S. Single wall carbon nanohorn as a drug carrier for controlled release. Chem. Phys. Lett. 461, 189-192 (2008). 
92 Tahara, Y., Miyawaki, J., Zhang, M. F., Yang, M., Waga, I., lijima, S., Irie, H. \& Yudasaka, M. Histological assessments for toxicity and functionalization-dependent biodistribution of carbon nanohorns. Nanotechnology 22, 265106 (2011).

93 Murakami, T. \& Tsuchida, K. Recent advances in inorganic nanoparticle-based drug delivery systems. Mini-Rev. Med. Chem. 8, 175-183 (2008).

94 Zhang, M. F., Yudasaka, M., Ajima, K., Miyawaki, A. \& Lijima, S. Light-assisted oxidation of single-wall carbon nanohorns for abundant creation of oxygenated groups that enable chemical modifications with proteins to enhance biocompatibility. Acs Nano 1, 265-272 (2007).

95 Xu, J. X., Zhang, M. F., Nakamura, M., lijima, S. \& Yudasaka, M. Double oxidation with oxygen and hydrogen peroxide for hole-forming in single wall carbon nanohorns. Appl. Phys. A 100, 379-383 (2010).

96 Desai, N. \& Hubbell, J. Solution technique to incorporate polyethylene oxide and other water-soluble polymers into surfaces of polymeric biomaterials. Biomaterial 12 , 144-153 (1991)

97 Du, H., Chandaroy, P. \& Hui, S. Grafted poly-(ethylene glycol) on lipid surfaces inhibits protein adsorption and cell adhesion. Biochim. Biophys. Acta 1326, 236-248 (1997)

98 Xu, J. X., lijima, S. \& Yudasaka, M. Appropriate PEG compounds for dispersion of single wall carbon nanohorns in salted aqueous solution. Appl. Phys. A 99, 15-21 (2010).

99 Muralkami, T., Fan, J., Yudasaka, M., lijima, S. \& Shiba, K. Solubilization of singlewall carbon nanohorns using a PEG-doxorubicin conjugate. Mol. Pharmaceut. 3, 407-414 (2006)

100 Matsumura, S., Ajima, K., Yudasaka, M., lijima, S. \& Shiba, K. Dispersion of cisplatin-loaded carbon nanohorns with a conjugate comprised of an artificial peptide aptamer and polyethylene glycol. Mol. Pharmaceut. 4, 723-729 (2007).

101 Matsumura, S., Sato, S., Yudasaka, M., Tomida, A., Tsruruo, T, lijima, S. \& Shiba, K Prevention of carbon nanohorn agglomeration using a conjugate composed of combshaped polyethylene glycol and a peptide aptamer. Mol. Pharmaceut. 6, 441-447 (2009).

102 Nakamura, M., Tahara, Y., Ikehara, Y., Murakami, T., Tsuchida, K., lijima, S., Waga, I. \& Yudasaka, M. Single-walled carbon nanohorns as drug carriers: adsorption of prednisolone and anti-inflammatory effects on arthritis. Nanotechnol. 22, 465102 (2011).

103 Murakami, T., Sawada, H., Tamura, G., Yudasaka, M., Iijima, S. \& Tsucbida, K. Waterdispersed single-wall carbon nanohorns as drug carriers for local cancer chemotherapy. Nanomedicine 3, 453-463 (2008).

104 Guerra, J., Herrero, M. A., Carrion, B., Perez-Martinez, F. C., Lucio, M., Rubio, N., Meneghetti, M., Prato, M., Cena, V. \& Vazquez, E. Carbon nanohorns functionalized with polyamidoamine dendrimers as efficient biocarrier materials for gene therapy. Carbon NY 50, 2832-2844 (2012).

105 Zhang, M., Murakami, T., Ajima, K., Tsuchida, K., Sandanayaka, A. S. D., Ito, O., lijima, S. \& Yudasaka, M. Fabrication of $\mathrm{ZnPc} /$ protein nanohorns for double photodynamic and hyperthermic cancer phototherapy. Proc. Natl Acad. Sci. USA $105,14773-14778$ (2008).

106 Maeda, H. Macromolecular therapeutics in cancer treatment: the EPR effect and beyond. J. Control Release 164, 138-144 (2012).

107 Miyawaki, J., Matsumura, S., Yuge, R., Murakami, T., Sato, S., Tonnida, A., Tsuruo, T., Ichihashi, T., Fujinami, T., Irie, H., Tsuchida, K., Iijima, S., Shiba, K. \& Yudasaka, M. Biodistribution and ultrastructural localization of single-walled carbon nanohorns determined in vivo with embedded Gd203 labels. ACS Nano 3, 1399-1406 (2009).

108 Zhang, M. F., Tahara, Y., Yang, M., Zhou, X., lijima, S. \& Yudasaka, M. Quantification of whole body and excreted carbon nanohorns intravenously injected into mice. Adv. Healthc. Mater. (epub ahead of print 5 July 2013; doi:10.1002/adhm. 201300192).

109 Zhang, M., Yudasaka, M., Miyawaki, J., Fan, J. \& lijima, S. Isolating single-wall carbon nanohorns as small aggregates through a dispersion method. J.Phys. Chem. B 109, 22201-22204 (2005).

110 Zhang, M. F., Zhou, X., lijima, S. \& Yudasaka, M. Small-sized carbon nanohorns enabling cellular uptake control. Small 8, 2524-2531 (2012).

111 Bondar, V. S., Pozdnyakova, I. O. \& Puzyr, A. P. Applications of nanodiamonds for separation and purification of proteins. Phys. Solid. State 46, 758-760 (2004).

112 Huang, L. L. \& Chang, H. C. Adsorption and immobilization of cytochrome c on nanodiamonds. Langmuir 20, 5879-5884 (2004).

113 Chung, P. H., Perevedentseva, E., Tu, J. S., Chang, C. C. \& Cheng, C. L. Spectroscopic study of bio-functionalized nanodiamonds. Diamond Relat. Mater. 15, 622-625 (2006)

114 Guan, B., Zou, F. \& Zhi, J. F. Nanodiamond as the pH-responsive vehicle for an anticancer drug. Small 6, 1514-1519 (2010).

115 Chen, M., Pierstorff, E., Lam, R., Li, S. Y., Huang, H., Osawa, E. \& Ho, D. Nanodiamond-mediated delivery of water-insoluble therapeutics. ACS Nano 3, 2016-2022 (2009)

116 Chow, E. K., Zhang, X. Q., Chen, M., Lam, R., Robinson, E., Huang, H. J., Schaffer, D. Osawa, E., Goga, A. \& Ho, D. Nanodiamond therapeutic delivery agents mediate enhanced chemoresistant tumor treatment. Sci. Transl. Med. 3, 73ra21 (2011).

117 Huang, H., Pierstorff, E., Osawa, E. \& Ho, D. Active nanodiamond hydrogels for chemotherapeutic delivery. Nano Lett. 7, 3305-3314 (2007).

118 Zhang, X. Q., Lam, R., Xu, X. Y., Chow, E. K., Kim, H. \& Ho, D. Multimodal nanodiamond drug delivery carriers for selective targeting, imaging, and enhanced chemotherapeutic efficacy. Adv. Mater. 23, 4770-4775 (2011).

119 Chang, Y. R., Lee, H. Y., Chen, K., Chang, C. C., Tsai, D. S., Fu, C. C., Lim, T. S., Tzeng, Y. K., Fang, C. Y., Han, C. C., Chang, H. C. \& Fann, W. Mass production and dynamic imaging of fluorescent nanodiamonds. Nat. Nanotechnol. 3, 284-288 (2008)

120 Fang, Y. X., Guo, S. J., Li, D., Zhu, C. Z., Ren, W., Dong, S. J. \& Wang, E. K. Easy synthesis and imaging applications of cross-linked green fluorescent hollow carbon nanoparticles. Acs Nano 6, 400-409 (2012).

121 Ganeshkumar, M., Ponrasu, T., Sathishkumar, M. \& Suguna, L. Preparation of amphiphilic hollow carbon nanosphere loaded insulin for oral delivery. Colloids Surf. $B$ 103, 238-243 (2013).

122 Zhu, J., Liao, L., Bian, X. J., Kong, J. L., Yang, P. Y. \& Liu, B. H. pH-controlled delivery of doxorubicin to cancer cells, based on small mesoporous carbon nanospheres. Small 8, 2715-2720 (2012).

123 Sayes, C. M., Marchione, A. A., Reed, K. L. \& Warheit, D. B. Comparative pulmonary toxicity assessments of $\mathrm{C} 60$ water suspensions in rats: few differences in fullerene toxicity in vivo in contrast to in vitro profiles. Nano Lett. 7, 2399-2406 (2007).

124 Zhao, Y. L., Xing, G. M. \& Chai, Z. F. Nanotoxicology: are carbon nanotubes safe? Nat. Nanotechnol. 3, 191-192 (2008).

125 Yan, L., Zhao, F., Li, S. J., Hu, Z. B. \& Zhao, Y. L. Low-toxic and safe nanomaterials by surface-chemical design, carbon nanotubes, fullerenes, metallofullerenes, and graphenes. Nanoscale 3, 362-382 (2011).

126 Sayes, C. M., Fortner, J. D., Guo, W., Lyon, D., Boyd, A. M., Ausman, K. D., Tao, Y. J., Sitharaman, B., Wilson, L. J., Hughes, J. B., West, J. L. \& Colvin, V. L. The differential cytotoxicity of water-soluble fullerenes. Nano Lett. 4, 1881-1887 (2004).

127 Xia, T., Kovochich, M., Brant, J., Hotze, M., Sempf, J., Oberley, T., Sioutas, C., Yeh, J. I., Wiesner, M. R. \& Nel, A. E. Comparison of the abilities of ambient and manufactured nanoparticles to induce cellular toxicity according to an oxidative stress paradigm. Nano Lett. 6, 1794-1807 (2006).

128 Nielsen, G. D., Roursgaard, M., Jensen, K. A., Poulsen, S. S. \& Larsen, S. T. In vivo biology and toxicology of fullerenes and their derivatives. Basic Clin. Pharmacol. Toxicol. 103, 197-208 (2008).

129 Zhang, W., Sun, B. Y., Zhang, L., Zhao, B., Nie, G. J. \& Zhao, Y. L. Biosafety assessment of Gd@C82(OH)22 nanoparticles on Caenorhabditis elegans. Nanoscale 3, 2636-2641 (2011).

130 Miyawaki, J., Yudasaka, M., Azami, T., Kubo, Y. \& lijima, S. Toxicity of single-walled carbon nanohorns. Acs Nano 2, 213-226 (2008).

131 Bacchetta, R., Tremolada, P., Di Benedetto, C., Santo, N., Fascio, U., Chirico, G., Colombo, A., Camatini, M. \& Mantecca, P. Does carbon nanopowder threaten amphibian development? Carbon. NY 50, 4607-4618 (2012).

132 Liu, K. K., Wang, C. C., Cheng, C. L. \& Chao, J. I. Endocytic carboxylated nanodiamond for the labeling and tracking of cell division and differentiation in cancer and stem cells. Biomaterial 30, 4249-4259 (2009).

133 Fang, C. Y., Vaijayanthimala, V., Cheng, C. A., Yeh, S. H., Chang, C. F., Li, C. L. \& Chang, H. C. The exocytosis of fluorescent nanodiamond and its use as a long-term cell tracker. Small 7, 3363-3370 (2011).

134 Sadzuka, Y. Effective prodrug liposome and conversion to active metabolite. Curr. Drug Metab. 1, 31-48 (2000).

135 Schipper, M. L., Nakayama-Ratchford, N., Davis, C. R., Kam, N. W. S., Chu, P., Liu, Z., Sun, X. M., Dai, H. \& Gambhir, S. S. A pilot toxicology study of single-walled carbon nanotubes in a small sample of mice. Nat. Nanotechnol. 3, 216-221 (2008).

136 Pietroiusti, A., Massimiani, M., Fenoglio, I., Colonna, M., Valentini, F., Palleschi, G., Camaioni, A., Magrini, A., Siracusa, G., Bergamaschi, A., Sgambato, A. \& Campagnolo, L. Low doses of pristine and oxidized single-wall carbon nanotubes affect mammalian embryonic development. Acs Nano 5, 4624-4633 (2011).

137 Poland, C. A., Duffin, R., Kinloch, I., Maynard, A., Wallace, W. A. H., Seaton, A., Stone, V., Brown, S., MacNee, W. \& Donaldson, K. Carbon nanotubes introduced into the abdominal cavity of mice show asbestos-like pathogenicity in a pilot study. Nat. Nanotechnol. 3, 423-428 (2008).

138 Kostarelos, K. The long and short of carbon nanotube toxicity. Nat. Biotechnol. 26, 774-776 (2008).

139 Roman, D. Yasmeen, A., Mireuta, M., Stiharu, I. \& Al Moustafa, A. E Significant toxic role for single-walled carbon nanotubes during normal embryogenesis. Nanomed-Nanotechnol. 9, 945-950 (2013).

140 Hougaard, K. S., Jackson, P., Kyjovska, Z. O., Birkedal, R. K., De Temmerman, P. J., Brunelli, A., Verleysen, E., Madsen, A. M., Saber, A. T., Pojana, G., Mast, J., Marcomini, A., Jensen, K. A., Wallin, H., Szarek, J., Mortensen, A. \& Vogel, U. Effects of lung exposure to carbon nanotubes on female fertility and pregnancy. A study in mice. Reprod Toxicol. 41, 86-97 (2013).

141 Chen, P. H., Hsiao, K. M. \& Chou, C. C. Molecular characterization of toxicity mechanism of single-walled carbon nanotubes. Biomaterial 34, 5661-5669 (2013).

142 Rodriguez-Yanez, Y. Munoz, B. \& Albores, A. Mechanisms of toxicity by carbon nanotubes. Toxicol. Mech. Method. 23, 178-195 (2013).

143 Mal, N. K., Fujiwara, M. \& Tanaka, Y. Photocontrolled reversible release of guest molecules from coumarin-modified mesoporous silica. Nature 421, 350-353 (2003)

144 Torney, F., Trewyn, B. G., Lin, V. S. Y. \& Wang, K. Mesoporous silica nanoparticles deliver DNA and chemicals into plants. Nat. Nanotechnol. 2, 295-300 (2007).

(c) (i) (3) $\ominus$ This work is licensed under a Creative Commons Attribution-NonCommercial-NoDerivs 3.0 Unported License. To view a copy of this license, visit http://creativecommons. org/licenses/by-nc-nd/3.0/ 


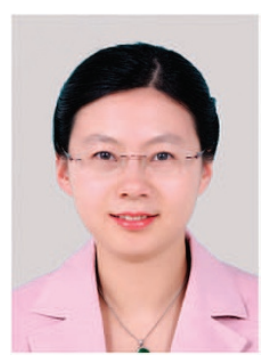

Jing Wang is a research assistant professor in the Laboratory for Biological Effects of Nanomaterials and Nanosafety, National Center of Nanoscience and Technology (NCNST), China. She obtained her MS degree in analytical chemistry in University of Delaware, 2011, with a focus on gold nanoparticle-enhanced surface plasmon resonance biosensor. Her current main research interest involves biomarker detection and validation in physiological fluids assisted by novel nanomaterials.
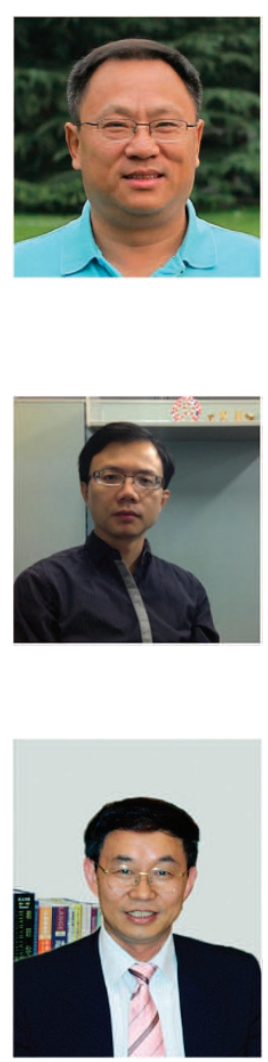

Zhongbo Hu got his BS in Materials Science from National University of Defence Technology in 1983, his MS in Electronics Physics from the Institute of Electronics, Chinese Academy of Sciences in 1986 and his $\mathrm{PhD}$ in Chemistry from University of MissouriColumbia in 1994. He worked as a post-doctoral fellow at Missouri University Research Reactor (MURR) from 1994 to 1996, as a postdoctoral research scientist at Argonne National Laboratory (ANL) from 1996-1998, as an engineer (1998-1999) and a senior engineer (1999-2001) at ComEd in Chicago. He joined the faculty of GUCAS in 2002 and is currently a Professor in Materials Science of College of Materials Science and Optoelectronics Technology, the University of Chinese Academy of Sciences. He has authored about peer-reviewed 100 papers.

Dr Jianxun Xu is an associate professor in Chinese Academy of Sciences Key Laboratory for Biomedical Effects of Nanomaterials and Nanosafety, National Center for NanoSciences and Technology of China. He obtained his Bachelors of Science and PhD degree from College of Chemistry and Molecular Engineering, Peking University in China under the supervision of Professor Zhennan Gu. Dr Xu's thesis work was focused on the synthesis and chemistry of nano-carbon materials. His researches were extended to the bio-medical applications and bio-mimetic integrated structures of nano-carbon materials during his postdoctoral training in Japan.

Yuliang Zhao is the Professor and Director, Chinese Academy of Sciences Key Laboratory for Biomedical Effects of Nanomaterials \& Nanosafety, Institute of High Energy Physics, Chinese Academy of Sciences (CAS). He also serves as the Deputy Director-General of National Center for Nanoscience and Technology of China, and the member of National Sterring Council for Nanosciences and Technology of China. His research interests mainly include Nanotoxicological Chemistry (nanotoxicology, cancer nanotechnology and nanochemistry), Nanobioanalytical Sciences and MD Simulations of biochemical processes on nano/bio interface. He has published more than 250 peer-reviewed papers and published/edited 11 books, including the 'Nanotoxicology' published in USA, 2007, the first textbook in the field of nanotoxicology. He was invited and has delivered more than 160 Invited Lectures at international conferences and universities. Professor Zhao is now serving as associate editors and international advisory editorial borad member for 8 SCI journals in USA UK, and Germany. 